\title{
Los dilemas morales qua límites de la racionalidad práctica
}

\author{
GUILLERMO LARIGUET \\ Consejo de Investigaciones Científicas y Técnicas de Argentina (Conicet) \\ Centro de Investigaciones de la Facultad de Filosofía y Humanidades \\ Universidad Nacional de Córdoba \\ glariguet@yahoo.com
}

Resumen: En este artículo se intenta mostrar de qué manera los dilemas morales pueden verse como límites de la racionalidad práctica. Se distinguen dos tipos de dilema: uno en que los requerimientos normativos son no derrotables y otro en que los requerimientos son prima facie. Luego se muestra cómo funciona en cada uno de estos tipos el desafío a una solución racional o respuesta correcta. También se discuten dilemas con componentes trágicos. Palabras clave: dilemas morales, requerimientos no derrotables, requerimientos prima facie, dilemas trágicos

\begin{abstract}
In this paper, I attempt to show in what way moral dilemmas can be seen as limits of practical rationality. I distinguish between two types of dilemma: the first type is based in normative requirements that are non defeasible; the second type, prima facie requirements. Then, I try to show in what way a rational solution or right answer can be affected by these types of dilemmas. In addition, I discuss dilemmas with tragic elements.
\end{abstract}

Key words: moral dilemmas, non overriding requirements, prima facie requirements, tragic dilemmas

[L]o trágico es meramente la consecuencia de una interpretación del mundo errónea [...], una especie de consternación [...] ante las imperfecciones del mundo [...], o - como dice Maeterlinck - siempre sólo consecuencia de que "no había un sabio cerca".

(Scheler 1961, p. 146)

Que la misma valentía o la misma audacia que permiten a un hombre realizar una proeza gloriosa, también lo expongan a un peligro [...] que lo aniquile [...]; que a veces veamos en la inclinación anímica idealista y valiosa de un hombre hacia los bienes del espíritu la razón por la cual fracasa - y debe fracasar - ante lo mezquino de la vida; que cada uno tenga, según expresión de Mme. de Stäel, "las imperfecciones de sus virtudes"; que los rasgos esenciales de su carácter hayan permitido al hombre alcanzar su máxima altura y al mismo tiempo hayan originado la "catástrofe" —eso es lo "trágico" en su sentido más eminente.

(Scheler 1961, p. 155)

Diánoia, volumen LV, número 64 (mayo 2010): pp. 71-108. 


\section{Introducción}

Desde Platón y Aristóteles, pasando por Kant y Hegel, la cuestión de los dilemas morales ha resultado una preocupación filosófica recurrente. Quizá le debamos a la filosofía analítica contemporánea una discusión más refinada al respecto, pues desde hace más de cuarenta años ${ }^{1}$

${ }^{1}$ La bibliografía sobre los dilemas morales es inmensa y siempre estará condenada a ser incompleta, sea que se exprese en un artículo, en un libro, o en varios artículos o libros. Pero para el presente trabajo baste, al menos, tener en cuenta la introducción de Gowans 1987 (pp. 3-33), el artículo de Peña (1991), la introducción de Mason 1996 (pp. 3-9) y Greenspan 1995 (especialmente las pp. 9-28), y Foot 2002, que es relevante no sólo para entender sus diferencias con Bernard Williams, sino para apreciar cómo una realista moral y ética de las virtudes responde al desafío de los dilemas en los términos planteados por Williams (1993), consistentes en ver los dilemas qua conflictos de deseos (no de creencias) y, por consiguiente, como brazo armado para tratar de dar jaque mate al realismo moral como doctrina cognoscitivista paradigmática en materia ética. Una compilación más reciente de la discusión sobre conflictos prácticos es la de Baumann y Betzler 2004, especialmente la introducción (pp. 1-26). Puede verse una discusión sistemática actualizada sobre dilemas morales en Bagnoli 2006a, por ejemplo. En Platts 2000 se encuentra una interesante compilación de trabajos de ética normativa sobre diversos dilemas éticos; véase especialmente la introducción de Platts (pp. 7-14). Para una fascinante discusión sobre los conflictos trágicos, pero desde una perspectiva psicoanalítica "ecléctica" (que incluye una combinación de diferentes autores como Freud, Lacan, Klein, etc.), véase Alford 1992. En Wenz 2007 se encuentra una presentación instructiva de filosofía política acerca de cómo el Estado debe lidiar —según la concepción filosófica que esté en juego- con diversos conflictos morales dilemáticos. Si lo que interesa es tener un registro de la discusión sobre dilemas en el ámbito del derecho constitucional, véanse Eskridge y Levinson 1998; Zucca 2007; Martínez Zorrilla 2007, y Barberis 2008. También podría ser interesante considerar la discusión filosófico-moral sobre dilemas en el ámbito del derecho penal que plantea Pollock 2004. Finalmente, para contar con una discusión sobre dilemas pero "teóricos" —esto es, como conjunto perspicuo de creencias descriptivas o explicativas que pueden ser verdaderas o falsas-, puede verse el clásico trabajo de Ryle 1962, especialmente la introducción (pp. 1-14). La distinción entre conflictos teóricos (entendidos como colisión de "creencias") y prácticos (entendidos como colisión de "deseos") defendida por Williams (1993) ha sido criticada principalmente por tres vías: en primer lugar, por considerar que los deseos son estados cognitivos al igual que las creencias y, por lo tanto, que son verdaderos o falsos (por ejemplo, Nussbaum 2005 y 2009); en segundo, por considerar que en el ámbito teórico también podría haber un tipo de residuo entendido como una duda irresoluble dado que ambas teorías exhiben fuentes de evidencia igualmente competentes. Para esto último estoy considerando un manuscrito inédito de Booth, a quien agradezco nuestra intensa discusión al respecto. La tercera vía es considerar que no hay una diferencia cualitativa entre conflictos teóricos y prácticos, y que en ambos casos, con los matices que correspondan a cada situación particular, es

Diánoia, vol. LV, no. 64 (mayo 2010). 
viene discutiendo sobre la naturaleza y la posibilidad ${ }^{2}$ de los dilemas morales.

Los dilemas morales son una forma de conflicto moral que puede experimentar un individuo o puede darse entre varios individuos. Estos conflictos involucran algún tipo de incompatibilidad normativa, sea que

necesario y posible realizar una investigación a fin de tratar de encontrar una salida a los dilemas, sean teóricos, sean prácticos. Ésta es una línea pragmática, de clara inspiración en Dewey, que se puede hallar, por ejemplo, en Levi 1997. Sobre este tema, véase también Ortiz Millán 2006.

${ }^{2}$ La discusión sobre la posibilidad e imposibilidad de los dilemas es compleja y profusa. En primer lugar, existen dos tipos de aproximaciones (De Haan 2001, p. 269 , n. 2; Vallentyne 1992), tanto para defender como para negar la posibilidad de dilemas: una racionalista o logicista, que hace hincapié en principios de lógica deóntica que deben regimentar el funcionamiento de nuestras obligaciones morales, y otra aproximación, empirista o fenomenalista, que apela a nuestra experiencia efectiva, según la cual parece que frecuentemente nos enfrentamos a dilemas de distinta intensidad y no parece el caso que esta experiencia constituya siempre un error masivo. En segundo lugar, los argumentos que suelen usarse en la discusión sobre la posibilidad de los dilemas no son concluyentes para ninguno de ambos bandos: ni para aquellos que los niegan (por ejemplo, Conee 1987), ni para aquellos que los defienden (por ejemplo, Barcan 1987). Esto sugeriría que, al momento de defender tesis fuertes sobre los dilemas, sólo seamos conscientes de las implicaciones que se sigan de nuestras tesis, aunque no podamos pretender convencer a todos los filósofos que participen en el debate con nosotros. En tercer lugar, hay que tener en cuenta que el tipo de argumentos que se puede blandir a favor o en contra de los dilemas es muy diverso y está afectado por el concepto de dilema implícito o explícito que se haya utilizado. Diría que existen dos tipos de argumentos en la discusión sobre la posibilidad o imposibilidad de los dilemas: a) unos que se construyen con pie en la lógica deóntica y, a su vez, esta lógica puede estatuir resultados diferentes según se conciba en un cálculo clásico deductivo (que respete leyes de modus ponens, refuerzo del antecedente, etc.), o según se conciba en términos de algún cálculo paraconsistente negando el principio ex falso quodlibet (Ausín 2005). Por lo general, la lógica deóntica deductiva (clásica) se ha usado para repeler la posibilidad conceptual de los dilemas y, por extensión, sostener que su posibilidad empírica es pura apariencia (véase, por ejemplo, De Haan 2001). Con la excepción de los lógicos paraconsistentes, otros lógicos clásicos admiten dilemas sosteniendo que la lógica puede ser concebida no con un papel justificatorio de nuestros razonamientos prácticos, sino más bien destacando su función heurística para dar cuenta de la realidad de los dilemas, buscando una representación que en el cálculo dé cuenta de la idea de mal inevitable que conllevan (Holbo 2002). b) Otros argumentos (Sayre-McCord 2009, pp. 14-23) obedecen a razones sustantivas como, por ejemplo, sostener que admitir dilemas "irresolubles" sería pensar muy mal de nuestra moral, pues significaría que ésta nos demanda cosas que no podemos cumplir. En cambio, con argumentos también sustantivos, diversos autores defienden que los dilemas son no sólo posibles, sino también valiosos para nuestra vida moral, por ejemplo, porque al ayudarnos a apreciar el carácter trágico de nuestras vidas, 
se entienda como relación de contradicción o simplemente de contrariedad. Los que defienden que los dilemas morales son algo más que un "simple" conflicto, esto es, un conflicto sólo definido a partir de cierta idea de incompatibilidad, sostienen que los dilemas encierran un plus. De acuerdo con esta concepción, un dilema moral será una forma "cualificada" de conflicto. De este modo, si bien es cierto que todo dilema involucra un conflicto, no es necesariamente cierto que todo conflicto involucre un dilema. El plus se puede explicar con diversas estrategias. Algunas de ellas enfatizan la "indeterminación" del discurso moral (encarnado en sistemas normativos, teorías morales normativas, etc.) para resolver los dilemas. Esta indeterminación se expresa en el hecho de que en los dilemas se manifiesta una ausencia de criterios, escalas o procedimientos racionales de solución que resulten plausibles. Otras estrategias —que son las que más me simpatizan— postulan que la ausencia de criterios, escalas o procedimientos es una cuestión contingente que no agota el plus. Podría incluso haber algunos criterios, pero éstos podrían ser controversiales. Pensemos, por ejemplo, en ciertos conflictos entre derechos fundamentales ${ }^{3}$ donde al menos dos individuos reivindicaran posiciones de valor igualmente atendibles. Supóngase que el juez que decide este conflicto encuentra que existe un criterio, escala o procedimiento racional; por ejemplo, alguna variante de balance, que le permite resolver el conflicto. La parte perdedora todavía podría seguir sosteniendo que la posición de valor que defendía era tan atendible como la de la posición triunfante. Por este tipo de posibilidades, esta otra estrategia aduce que lo importante no es mirar si hay o no hay criterios, escalas o procedimientos de solución de dilemas, sino mirar más bien qué se ha "perdido" o sacrificado con la decisión adoptada por el agente o los agentes morales involucrados en el conflicto. Esta tesis parece más interesante que la anterior, ya que nos vuelve conscientes de la posibilidad de que, de la mano de cualquier procedimiento, estemos sacrificando bienes valiosos. Con otras palabras, según esta concepción, es mejor enfatizar el sacrificio de alternativas valiosas y advertir que muchas veces se da una especie de paradoja, pues es la "solución" a

no distorsionan nuestra experiencia real de los conflictos ni el auténtico dolor que nos producen (por ejemplo, Hill 1996, p. 181).

${ }^{3}$ En este punto resulta pertinente la lectura de Rowan 1999, que discute diversas implicaciones morales que surgen de las políticas aplicables a conflictos sociales suscitados en torno a cuestiones como la acción afirmativa, la pornografía o el aborto, así como sus implicaciones para la teoría moral a la luz de distintas concepciones sobre la estructura de los derechos. Para un estudio de esta última cuestión, véase Cruz Parcero 2007.

Diánoia, vol. LV, no. 64 (mayo 2010). 
los conflictos dilemáticos la misma que entraña un sacrificio inevitable de un bien valioso. Esta estrategia me parece más atractiva, aunque no excluyente de la anterior, por su capacidad más generosa de dar cuenta de dilemas no sólo en instancias donde se verifique inconmensurabilidad o simetría, sino también allí donde, aun si hubiera conmensurabilidad, algo importante podría dañarse o sacrificarse. Articular esta concepción nos quita la venda de los ojos y nos permite ver más casos dilemáticos que si sólo nos restringiéramos a hipótesis estrictas de indeterminación producidas por supuestos de inconmensurabilidad o simetría. Mi tesis es perturbadora, pues sostiene que, incluso si hay conmensurabilidad, necesitamos otros argumentos para mostrar que no enfrentamos algún otro tipo de dilema desafiante donde un sacrificio relevante esté en juego.

Adoptaré una definición amplia de dilema moral (que en general todo filósofo pueda aceptar como punto de partida) según la cual hay un dilema cuando un agente $S$ se enfrenta a dos requerimientos normativos (normas, valores, principios morales, etc.) que lo obligan a realizar, o a abstenerse de realizar, dos comportamientos que resultan incompatibles. La satisfacción de un requerimiento impide la satisfacción del otro. ${ }^{4}$ En principio, ambos requerimientos son igualmente atendibles; sin embargo, el agente no puede realizar ambos a la vez. Por ejemplo, en la República, por medio de un diálogo entre Céfalo y Sócrates, Platón cuenta el dilema de un hombre que tiene que determinar si devuelve o no el arma que le ha prestado un amigo. El dilema surge porque el amigo ha enloquecido y podría dañarse a sí mismo y/o dañar a los demás. Por un lado, este hombre tiene ante sí el deber de devolver los préstamos (en este caso, el arma) y, por otro lado, el deber de salvaguardar a un amigo de un probable daño (Platón 1993, libro I). ${ }^{5}$

\footnotetext{
${ }^{4}$ Por esto, ciertos autores (como Lemmon 1987, p. 107) proponen abandonar el principio "debe implica puede".

${ }^{5}$ Dejo a un lado la cuestión de que a veces sería factible que el agente articulara una ordenación en el tiempo de estos requerimientos de tal modo que los satisficiera diacrónicamente. Una propuesta de este estilo, bajo la idea de "distribución de compensaciones", se encuentra en Anderson 1997, p. 92. Me parece que la propuesta de Anderson podría funcionar para ciertos conflictos, pero es dudoso que lo haga para todos, especialmente para aquellos dilemas que exigen una decisión en cierto momento y dicha decisión no admite una distribución temporal. Sin embargo, a veces distribuir compensaciones podría funcionar. Por ejemplo, en el caso del ejemplo de Platón, quizá el amigo podría posponer la devolución del arma hasta que la locura del prestamista pase o se cure. ¿Pero qué ocurre si ésta no puede curarse?
} 
¿Por qué los dilemas morales son objeto de tanto interés en la filosofía? Mi respuesta es que este interés obedece a que los dilemas ponen al desnudo posibles límites en la llamada racionalidad práctica. ${ }^{6}$ Una manera menos pomposa de decir esto es señalando que el límite principal

En fin, parece que Anderson necesita suministrarnos una teoría que discrimine en qué casos funcionaría su propuesta y en qué casos no.

${ }^{6}$ Esta expresión, "racionalidad práctica”, que también forma parte del título de este artículo, requiere que se le hagan importantes cualificaciones, atendiendo tanto a las muy pertinentes observaciones que efectuó el árbitro que hizo su informe en inglés, como a otros filósofos que me han interrogado acerca de este punto. En primer lugar, tiene razón Faviola Rivera cuando me pregunta por qué hablo de "racionalidad práctica" y no de "teorías morales", por ejemplo. Así, mi trabajo podría titularse "Los dilemas... y los límites de nuestras teorías morales", aunque podría pensarse en los límites de la propia moral sin presuponer que necesariamente haya mucha teoría moral implícita en ella o una teoría moral determinada y dominante dentro de ella (Platts 2006, p. 56). Me apresuro a aclarar que mi afirmación no pretende implicar un reduccionismo del entendimiento de la ética o la moral sólo a la idea de una racionalidad práctica (entendida a priori, o como conjunto de razones intersubjetivamente compartido, o lo que fuere). Estoy de acuerdo en este sentido con la cautela de Mark Platts (1999, p. 145) cuando nos previene de distorsionar la moral mediante abstracciones que la reduzcan a una sola característica, olvidando, en contra de lo que previene Charles Larmore (2001), su complejidad. Atento a estas sugerencias, debo aclarar que mi intención de usar en el texto y en el título la expresión "racionalidad práctica" no obedece a ningún propósito de reducción, sino que tengo en mente algo mucho más sencillo: la idea de que si los dilemas son "desafíos", tales desafíos "imposibilitan", como mostraré para el primer tipo de dilemas que caracterizaré en el texto, o "dificultan mucho", para el segundo tipo de dilemas que caracterizaré en el texto, que el agente o los agentes morales puedan tener bases aceptables para concluir qué deben hacer. Para la mayor parte de las teorías morales, quizá en cierta idealización de cómo ocurren realmente las cosas en la práctica, tal conclusión surge de la mediación de un razonamiento o deliberación práctica: una deliberación que parte de una premisa mayor (normativa) -o más de una-, una descripción factual o más de una (la premisa menor) y una conclusión práctica. Es decir, que con la expresión "racionalidad práctica" estoy sugiriendo que si nos enfrentamos a alguno de los tipos de dilema que discerniré en el texto, el paso de las premisas mayor y menor a la conclusión práctica se halla obstruido y, por esto, la decisión del agente, o bien no cuenta con un apoyo debidamente justificado, o bien su justificación es altamente discutible y difícilmente aceptable por otro agente que estuviera en circunstancias semejantes (Winch 1972, p. 161). También debería decir que los dilemas, especialmente los de índole trágica, ponen en entredicho, más que a nuestras teorías, a nuestra propia agencia autónoma soberana o virtuosa. Puede haber casos en que el agente no haya elegido la situación de encerrona en que se encuentra y el resultado de su elección está condenado por un estado determinado del mundo a ser inevitablemente malo. Con independencia de Rivera, aquí podría añadir entonces, y no tendría empacho en hacerlo, un largo etcétera en lo que a límites se refiere cuando son dilemas morales los que están en

Diánoia, vol. LV, no. 64 (mayo 2010). 
es que el agente parece fracasar en identificar criterios plausibles para dar una "solución racional" o "correcta" a esta clase de conflicto moral. Existen diversas maneras de dar cuenta de este límite; por ejemplo, diciendo que los dilemas son conflictos "irresolubles". No toda teoría

juego. Este largo etcétera avala una sugerencia del árbitro cuyo informe fue redactado en inglés, sugerencia con la cual coincido plenamente, y es que "necesitamos oír más acerca de la racionalidad práctica, más que restringirnos a estrategias específicas de solución racional". Desde luego, la categoría de racionalidad práctica tiene una capacidad de comprender muchas situaciones problemáticas diferentes $\mathrm{y}$, por lo tanto, son muchas más las estrategias para enfrentar estas dificultades que pueden estar en juego de las que yo considero en mi texto. Empero, necesito hacer una segunda importante aclaración con respecto al señalamiento de este árbitro. El espíritu de este trabajo es procurar mostrar algunos de los "desafíos" que los dilemas suscitan en nuestras vidas y, por consiguiente, me preocupo más por determinar en los grupos de dilemas que, a juicio de ambos árbitros, distingo adecuadamente qué cuenta negativamente como imposibilidad o gran dificultad de "solución racional", antes de situarme en el "revés de la trama" y especificar qué podría contar positivamente como "solución racional", tal como lo sugiere agudamente mi árbitro del informe en inglés. Pero el hablar de qué pueda contar como "solución racional" parece presuponer que el dilema es resoluble racionalmente, sea cual fuere el significado del término racional, y esto es justamente lo que los dilemas ponen en entredicho. Precisamente, las dos concepciones acerca de cómo reconstruir el desafío de los dilemas que brevemente presento en el cuerpo del texto con las ideas de "indeterminación" y "sacrificio" apuntan en la dirección de enfatizar los desafíos - lo que cuenta como ausencia de solución racional o gran dificultad para alcanzarlay no lo que cuenta como "solución racional". Aunque debo decir que, si se atiende en mi texto a cuáles son las bases para considerar cuándo una solución racional es imposible o muy difícil, podría colegirse, por reversión, qué contaría bajo estas hipótesis específicas como solución racional. Casualmente, el árbitro que hizo su informe en español pondera como virtud del texto el hecho de que establezco claramente la conexión entre tipos claros de dificultad de solución racional y tipos de dilema. Es por lo anterior que coincido con el otro árbitro (del informe en inglés) en que una "solución racional", en el sentido de señalar cuál es el "cuerno que correctamente hay que elegir", implica que no estamos ante un verdadero dilema, sino ante un conflicto simple o simpliciter, o también, quizá, ante lo que en el texto llamo un falso dilema. Justamente éste es uno de los puntos centrales de mi texto cuando distingo conflictos simples de dilemas auténticos, ya que apunto a que, en los dilemas auténticos, la solución "correcta" o "racionalmente justificada" o bien es imposible, o bien muy problemática: el primer caso se debe a la existencia de requerimientos no derrotables mutuamente; el segundo, a la idea de que, aunque son derrotables, su solución se apoya en el llamado "balance", que más que una categoría clara de solución sigue siendo un problema filosófico abierto, por el tipo de razones que alego en el texto. Cabe añadir que la intuición más extendida en filosofía práctica, con todo, es que una solución racional o correctamente justificada no es aquella que identifica cuál es "el" cuerno del dilema que hay que asir, sino que se trata de otra cuestión. La cuestión es que se parte, por hipótesis, de la

Diánoia, vol. LV, no. 64 (mayo 2010). 
moral acepta que los dilemas expongan este tipo de límites, como las teorías deontologistas de raigambre kantiana, que tienden a negarlos. ${ }^{7}$ La negación se basa en un rechazo al fenómeno mismo de los dilemas bajo el lema "obligationes non colliduntur". Precisamente, ciertos autores (McConnell 1978, p. 269; también McConnell 2002) sostienen que una teoría moral es "adecuada" si logra guiar siempre hacia una respuesta correcta para todos nuestros problemas morales. "Guiar" es una función normativa que, si se acepta la posibilidad de los dilemas, podría estar en tensión con la función explicativa de nuestras teorías morales: dar cuenta de los límites reales que ciertos conflictos morales ponen en nuestras vidas. En este trabajo pasaré por alto la discusión acerca de qué cuenta como una teoría moral adecuada. A título de experimento mental, voy a suponer que los tipos de dilema moral que trataré en este texto son posibles a fin de mostrar, en primer lugar, cómo funcionaría la idea del límite, esto es, la falta o gran dificultad —-según el casopara encontrarles solución racional. En segundo lugar, quiero mostrar que la cuestión del límite está lejos de ser clara por dos motivos.

El primer motivo es que existen distintas maneras de construir tipos específicos de dilema a partir del concepto amplio que ofrecí. La diferencia entre tipos de dilema se construye a partir de dos aspectos que se pueden distinguir. Por un lado, existen diversos modos de reconstruir el

intuición de que ambas alternativas son exigibles; por lo tanto, asirse a un cuerno no puede contar como la solución correcta. Los mejores candidatos, sea cual fuere la expresión que se use, o tradición o autor que se cite, son aquellos que buscan una salida "intermedia" entre ambos cuernos de tal modo que intente satisfacer, al menos mínimamente, ambos cuernos u opciones. Esta salida "entre los cuernos" consiste en el ideal más alto y, por ello, quizá más difícil de aplicar a los dilemas más problemáticos o trágicos con que nos enfrentamos, ya que es un ideal que exige la conciliación, armonía, coherencia, convergencia, unidad o convergencia entre ambas alternativas de tal modo que no defraude completamente ninguna y que no refrende una inconsistencia práctica. Buena parte de estas expresiones de coherencia podrían resumirse, mutatis mutandis, con la idea de "equilibrio reflexivo ampliado" que defiende Richardson 1997, pp. 183-184 y 188. En la nota al pie 36 de este artículo, en que distingo dos sentidos en la operación de considerar "todos los factores relevantes" de una decisión, se aclaran parcialmente las dos fuentes de dificultades para obtener la ansiada coherencia. Por último, es importante notar que hay autores agudos como Barcan (1987, pp. 188-204), que han argüido que para que enfrentemos dilemas auténticos ni siquiera es perentorio el requisito de "inconsistencia": el sistema podría ser consistente, pero el agente podría enfrentarse a auténticos dilemas surgidos de eventos producidos en el mundo, lo cual puede incluir también conductas del propio agente.

${ }^{7}$ Una interpretación diferente, según la cual la teoría kantiana podría aceptar ciertas "lagunas", puede verse en Hill Jr. 1996, pp. 179-183.

Diánoia, vol. LV, no. 64 (mayo 2010). 
estatus de los requerimientos normativos en conflicto (por ejemplo, o bien como prima facie, o bien como no derrotables). Por el otro, existen diversos modos de capturar la naturaleza del límite. Mientras cierta estrategia enfatiza la ausencia de criterios en nuestras teorías morales para determinar cuál es el requerimiento que debe seguir el agente, otra estrategia sostiene que la cuestión de la ausencia es contingente. El punto es que aun si este criterio a veces estuviera disponible, no se eliminaría el sacrificio de un requerimiento normativo moralmente atendible.

El segundo motivo es que la discusión sobre qué tipo de dilema moral está en juego afecta la idea de qué tipo de "solución" es posible o no es posible. Por lo tanto, existen diversos sentidos en los que una solución racional podría ser cuestionada en el contexto de un dilema moral.

La estructura del trabajo es la siguiente. En primer lugar mostraré un tipo de dilema moral en el que se verifica una relación de inconmensurabilidad o simetría entre los requerimientos. Sostendré que la manera adecuada de entender el estatus de estos requerimientos es mediante la idea de requerimientos no derrotables. A partir de esta idea expondré de qué modo se puede cuestionar una respuesta correcta para estos dilemas. En segundo lugar mostraré que hay otros dilemas morales donde las ideas de inconmensurabilidad o simetría no son necesarias. Sostendré que la manera adecuada de entender el estatus de estos requerimientos es mediante la idea de requerimientos prima facie. A partir de esta idea expondré de qué modo se encuentra cuestionada una respuesta correcta para estos dilemas. También introduciré la idea de que puede haber dilemas morales "trágicos". Ésta es una especie de categoría "ubicua", ya que lo trágico a veces se considera graduable y a veces no.

\section{Los dilemas con requerimientos no derrotables y el problema de su solución racional}

Si dos requerimientos no pueden cancelarse mutuamente, esto significa que ambos requerimientos se entienden como no derrotables; ninguno de ellos tiene la potencia para derrotar al otro. ${ }^{8}$ Dicho de otra manera, esto significa que los dos requerimientos son adoptados como

${ }^{8}$ Con el término "no derrotable" (que uso como equivalente de "inderrotable", "no superable", etc.) estoy recogiendo una intuición y modo de hablar ampliamente utilizado y compartido en filosofía moral (por ejemplo, McConnell 2002, p. 2). No discutiré aquí si los requerimientos en cuestión asumen la forma de condicionales inderrotables o, lisa y llanamente, de incondicionales inderrotables (los clásicos "de- 
"absolutos". Suponiendo que ciertos dilemas morales de esta clase sean posibles, existen dos alternativas para comprender el estatus de requerimientos no derrotables. La primera es la idea de "inconmensurabilidad"; la segunda, la idea de "simetría".

Dos requerimientos son inconmensurables cuando no existe un metacriterio (o valor comprehensivo) que permita determinar cuál de dos requerimientos, $A$ y $B$, es más fuerte, menos fuerte o tan fuerte como el otro. Existen diversos ejemplos de inconmensurabilidad en la literatura. Uno que se suele invocar como tal es el del "estudiante de Sartre" (Sartre 2003, pp. 21-22), que tiene que determinar si se queda a cuidar a su madre contrita o si se une a la resistencia francesa contra los nazis.

Dos requerimientos son simétricos cuando ambos compiten con la misma fuerza y no existe un metacriterio para preferir uno de los dos; también cuando compiten con la misma fuerza dos instancias incompatibles surgidas de un mismo requerimiento. Existen diversos ejemplos de simetría en la literatura. Uno muy conocido es el caso de la "decisión de Sofía" (novela de Styron). Sofía es una judía que está recluida en un campo de concentración nazi junto a sus dos hijos. Un guardia nazi le ordena que decida cuál de los dos irá a la cámara de gas y, en consecuencia, que decida cuál de los dos seguirá viviendo. El problema es que ninguna estrategia plausible permitiría concluir que un hijo tiene menos o más valor que el otro. Se supone que ambos tienen el mismo valor moral.

Los dos tipos de dilema moral mencionados son los que se invocan en general para sostener que existen conflictos morales "racionalmente irresolubles". Por imposibilidad de solución racional se entiende la inexistencia de un metacriterio que todos puedan aceptar para ordenar las preferencias; por ejemplo, en términos de propiedades como la de "mayor fuerza" de un requerimiento con respecto al otro. Cuando se afirma que es imposible una solución racional no se afirma que no haya algún tipo de "solución". Una característica de la filosofía práctica consiste en que el agente moral siempre está constreñido a decidir, incluso cuando omite actuar. Por ejemplo, supóngase el caso propuesto por Williams de un hombre (Jim) que en la selva se encuentra con otro que está a punto de matar a veinte personas. El inminente asesino le dice a Jim que si él mata a uno de esos hombres se salvará el resto. Al optar por seguir caminando, Jim omite hacer lo que el asesino le demanda; el resultado: mueren los veinte hombres (Williams y Smart 1973, p. 222).

beres categóricos"). Para una discusión de estas distinciones, véase Moreso 2002, pp. 236-239.

Diánoia, vol. LV, no. 64 (mayo 2010). 
Entonces, para estos casos de dilema moral es necesario distinguir solución racional de solución. Ante todo, es preciso señalar que afirmar que hay dilemas que se "solucionan" no autoriza a pensar que, por este solo hecho, tales dilemas son "aparentes". Esto es un non sequitur en el que a veces se incurre en la filosofía moral. En efecto, decir que hay un dilema que hay que solucionar presupone que hay un conflicto auténtico. Sólo se solucionan conflictos auténticos. Harina de otro costal es qué tipo de solución sea ésta, qué calidad racional exhiba y cuánto se ajuste a nuestros ideales de solución admisible en la moral.

Me atrevo a decir que el ideal fuerte en la teoría moral es que nuestros problemas morales se resuelvan en sentido "pleno". Una solución es "plena" cuando no deja residuo normativo. ${ }^{9}$

En cualquier caso, si los conflictos auténticos se resuelven, los conflictos aparentes se disuelven: no se resuelven. Un conflicto es aparente (o falso) cuando, en rigor, no había dos alternativas en colisión sino una sola alternativa en juego. Ésta es la estrategia que ciertos filósofos morales defenderían bajo la idea de que los agentes sólo están regidos por una sola obligación moral genuina, auténtica, completa, etc. (De Haan 2001, p. 268). Empero, conviene ir sin prisa. Cuando se afirma que los dilemas —que involucran requerimientos inconmensurables o simétricos- no tienen solución racional, no se está pensando en que el agente moral (si es un dilema experimentado por un individuo o varios) no pueda dar razones o argumentar en favor de alguna de las alternativas. En el caso del dilema experimentado por un individuo, éste podría preferir un valor (por ejemplo, el de trabajar en el Instituto de Investigaciones Filosóficas en vacaciones) al valor de estar más tiempo con su familia en vacaciones. Esa preferencia se justifica en las razones que forman parte del dominio del valor escogido. En este sentido, la solución al conflicto tiene alguna racionalidad: la suministrada por las razones que apoyan el valor preferido. Sin embargo, ¿cuál es la fuente que respalda esa preferencia? La respuesta es que si hay inconmensurabilidad o simetría, no hay tal fuente, y de allí surge la idea de que estos dilemas no tienen solución racional. Es decir: el agente puede escoger una alternativa siendo consciente de todas las razones que subyacen a

${ }^{9}$ La idea de solución plena puede operar en hipótesis donde no haya conflicto moral, en cuyo caso hay una sola obligación y no existe problema para determinar lo que el agente moral debe hacer; por lo tanto, no hay ningún residuo normativo. En cambio, en hipótesis donde hay un conflicto moral, una manera de articular la solución plena implicaría mostrar que hay una suerte de tercera vía que permite satisfacer coherentemente ambos requerimientos normativos, al menos parcialmente. Sobre esta idea, véanse, por ejemplo, Günther 1995, y Maliandi 2006.

Diánoia, vol. LV, no. 64 (mayo 2010). 
la alternativa preferida. Esto haría que el agente obrara considerando una opción a la luz de todas las razones relevantes que apoyan el valor preferido, pero esta elección no tendría más fundamento que las razones que subyacen a la alternativa preferida. Ocurre, sin embargo, que el agente se enfrenta a un conflicto entre dos alternativas que él mismo juzga que deben honrarse, razón por la cual parece necesitarse un metacriterio que esté por encima de las razones subyacentes al dominio de cada uno de los valores en conflicto. La idea de racionalidad esperada en la solución a un conflicto exige que el agente se apoye en un metacriterio aceptable que le permita comparar ambas alternativas a fin de determinar cuál es más fuerte. Al no encontrarse disponible este metacriterio, se vuelve problemático explicar cómo es factible una solución racional en estos casos. ${ }^{10}$

Pasa algo semejante cuando el conflicto se articula a partir de un conflicto entre individuos. Pensemos en los debates acalorados de la gente sobre la permisión o prohibición moral del aborto. Cada parte del conflicto parece tomar en forma absoluta su posición de valor (la vida de la madre o la vida del feto, ${ }^{11}$ según sea el caso). ${ }^{12}$ Un ideal de la razón práctica podría ser que, si es cierto que cada posición de

${ }^{10}$ Aunque todavía estaría abierta la posibilidad de tornar inteligible la elección del agente.

${ }^{11}$ Para un examen de la historia de la doctrina católica sobre el aborto, véanse Hurst 2002, pp. 7-36, y Ortiz Millán 2008.

${ }^{12}$ Estoy simplificando notablemente la discusión sobre el aborto a fin de mostrar que no es infrecuente que las partes de este conflicto presenten sus tesis de valor como absolutas; empero, la discusión de tesis de valor contrapuestas podría tomar una forma no absoluta. Por ejemplo, es común que en la discusión refinada sobre el aborto que podamos encontrar en la justicia — qua foro público de debate moral y jurídico - los contendientes presenten diversos tipos de argumentos — científicos, metafísicos, éticos- para mostrar en qué condiciones una posición debe triunfar sobre la otra. "Triunfar" podría significar que una posición revele tener "más peso" que la otra, aunque esta última algo tenga que decirnos a título de pérdida o residuo moral de algún grado de importancia. (Un análisis del tema del aborto y el problema de la pérdida moral que se sigue de elegir alguna de las alternativas en disputa — sensibles a la mujer o al feto- puede verse en Quinn 1984). Por esto, en el ámbito judicial el aborto se suele enfocar como una contienda representada a través de un "conflicto de derechos": por ejemplo, el derecho de la mujer a disponer libremente de su propio cuerpo, al menos para los primeros tres meses de gestación del feto y el derecho del feto a vivir. (Para un análisis de este enfoque, así como de los enfoques metafísico y ético, véase Valdés 2004; con el mismo enfoque, pero defendiendo el "mayor peso" del derecho de la mujer a abortar sobre otro tipos de derechos del feto, véase Thomson 2001, pp. 187-207). Ahora bien, en cuanto se admite que hay un conflicto de derechos, de alguna forma aparecerá una discusión de argumentos filtrada por algún tipo de ejercicio de "ponderación" de derechos.

Diánoia, vol. LV, no. 64 (mayo 2010). 
valor tiene un núcleo de verdad moral, ambas posiciones sean satisfechas. Éste es el ideal de la solución racional en sentido más fuerte, un ideal que en estos casos se encuentra bloqueado dado que no es posible "aglomerar"13 ambas alternativas o satisfacer en forma completa ambas alternativas. El hecho de que no sea posible aglomerar ambas alternativas sugiere que a veces nuestro mundo moral se manifiesta como si estuviera "fragmentado", ${ }^{14}$ lo cual es especialmente inteligible bajo la idea de conflictos entre requerimientos inconmensurables. Pero como asumimos esta fragmentación, parecemos asumir que ambas opciones inconmensurables son valiosas, forman parte de nuestro mundo moral y son atendibles.

Aunque las partes de un conflicto así serían reticentes a aceptar tirar la moneda o admitir que no queda otra cosa que lo que filósofos à la Kierkegaard llamarían una elección radical, parece que una solución racional, en el sentido ideal antes expresado, es imposible. Toda solución tendrá un defecto congénito. Si una parte prefiere el valor de la vida de la madre, la elección de este valor estará prohibida por las razones o normas que subyacen al otro valor, y viceversa.

Algunos filósofos pueden seguir sosteniendo el ideal de que es necesario lograr un acuerdo racional entre estas partes del conflicto. Quizá en posiciones moderadas sea posible, a veces, la disposición a encontrar una suerte de "tercera vía" en que ambos valores sean satisfechos parcialmente. Por ejemplo, que una parte acepte el aborto, pero que lo haga bajo ciertas condiciones que a ambas partes les parezca razonable ${ }^{15}$ establecer. Sin embargo, es un hecho que puede haber un desacuerdo

Más adelante me referiré a algunas de las dificultades conocidas a que nos enfrenta el ejercicio de ponderación.

${ }^{13}$ Diversos autores han propuesto abandonar la aglomeración (por ejemplo, Williams 1987, pp. 188-204). Otros autores proponen la disyunción excluyente como una "solución" a estos conflictos (véase McConnell 2002, p. 6). Mi tesis es que si uno es amigo de los dilemas morales, en el sentido de que éstos representan un desafío para alcanzar una solución racional, no puede usarse el argumento de la disyunción, que más que resolver "disuelve" el problema. Porque, por ejemplo, decir que Sofía no enfrenta en realidad un dilema genuino, ya que, por disyunción, está obligada a salvar a un hijo $o$ salvar al otro, se estaría falsificando el problema. Ambos hijos tienen el mismo valor. Si Sofía no tiene ningún metacriterio para determinar qué debe hacer, y que toda teoría moral pueda aceptar, la disyunción no resuelve nada; en todo caso, su pretensión es disolver un problema auténtico. Coincide con este punto de vista crítico Sinnott-Armstrong (1988, p. 56).

${ }^{14}$ Véase Nagel 1987, que habla de fragmentación de valores. Greenspan (1995, pp. 58-65) habla de una "fragmentación deóntica".

${ }^{15}$ Esta demanda de razonabilidad requiere una actitud cognitiva y afectiva de estar dispuesto a escuchar los argumentos discrepantes y buscar vías intermedias 
sobre si este tipo de condiciones es ejemplo de razonabilidad. Para algunos es razonable practicar un aborto sólo cuando haya riesgo de que la madre pierda la vida; para otros, esa restricción no es imprescindible y están abiertos a la alternativa de permitir el aborto durante los tres primeros meses sin que medie un peligro cierto o probable para la vida de la madre, etc. En cualquier caso, la decisión en favor de un valor entrañará un sacrificio del otro valor. El valor sacrificado puede ser considerado como un "residuo normativo" de la decisión adoptada. ${ }^{16}$

de acuerdo. Acerca de esta posición, véase, por ejemplo, Habermas 2006; Zucca y Cvijic 2004, y Zucca 2009, pp. 1-18.

${ }^{16}$ Aquí uso la idea de residuo de un modo más bien laxo, pues no necesito comprometerme con la enorme discusión metaética que existe en torno a cómo caracterizar mejor su naturaleza y tipo de conexión con los dilemas morales. Creo que es esencial a los dilemas el tema del residuo, y en tal sentido defendería una estrecha conexión entre dilemas y esta categoría; mi aporte, si es tal, está más bien basado en el esfuerzo de mostrar la importancia de distinguir si el residuo es graduable o no. No obstante, se podría decir que, en general, existen tres grandes concepciones sobre el residuo moral: la que denominaría psicologista, la normativista y la intermedia. La psicologista se presenta en dos versiones: una que llamaría "emocionalista" y otra "pura". La "emocionalista" sostiene que cada vez que experimentamos una sensación de agobio, culpa, remordimiento, tristeza, etc., es muy probable, si no seguro, que estemos ante un dilema. La versión que conecta dilemas y residuo mediante un bicondicional necesario ha sido muy cuestionada con el argumento de que tal conexión es meramente contingente. Podríamos experimentar estos estados afectivos sin que necesariamente estemos frente a un dilema. La versión "pura" trata de salvar la objeción anterior sosteniendo que los dilemas, especialmente trágicos, son fenómenos objetivos, independientes del agente, y la "tristeza trágica" es una característica esencial que acompaña los conflictos trágicos. Tal tristeza trágica no es concebida como algo emocional, al menos no en el sentido anterior de culpa o remordimiento, sino como una "serenidad" y aceptación de lo ocurrido (Scheler 1961, pp. 154-159).

La concepción normativista dice que el residuo ha de entenderse en sentido estrictamente normativo, es decir, identificando la alternativa que ha sido sacrificada (dejada a un lado) por la decisión del agente. La versión normativista, a su vez, podría ser considerada en dos formas. Una fuerte que sólo considera las alternativas normativas inevitablemente vulneradas por las decisiones de los agentes, y una débil que pone énfasis en el aspecto normativo sin que necesariamente desdeñe el valor explicativo o testimonial de la concepción psicologista. Por último, la concepción intermedia, defendida por ejemplo por algunos éticos de la virtud, sostiene que el fenómeno del residuo es una "bisagra" entre las dos concepciones anteriores. Se debe considerar el elemento normativo preterido por la decisión del agente, así como el aspecto psicológico que el agente reporta con la expresión de cierto estado emocional. Dicho estado no es un dato empírico bruto, sino un dato empírico cargado de una evaluación imputada por el propio sistema moral de que se trate (sobre esto último, véase Copp 2001, pp. 231-235, entre otros). Por

Diánoia, vol. LV, no. 64 (mayo 2010). 
Pero, ante todo, conviene decir que existen dos tipos diferentes de sacrificio. En los casos de inconmensurabilidad o simetría, el sacrificio no es visto como algo "graduable" y, por lo tanto, el residuo normativo tampoco es graduable. Se trata de un sacrificio concebido como absolu-

ejemplo, un sistema moral cortado al filo de una teoría de las virtudes esperaría que los agentes tuvieran la necesidad —y se las imputaría — (un kantiano diría el "deber") de sentir cierto estado apropiado y pertinente por la decisión trágica que han debido o han sido forzados a adoptar. Esta concepción tiene dos aspectos que considerar: en primer lugar, es una manera de preservar la virtud de los virtuosos de la mala fortuna moral; en segundo, es una manera de mostrar "deferencia indirecta" por la alternativa normativa exigible dejada a un lado, algo que justamente no hizo Agamenón cuando decidió sacrificar a Ifigenia y esto es lo que hace "ruido" en el coro que lo tilda de loco por no sentir nada por la decisión que ha tomado. (Agradezco a Andrea Lozano el haberme recordado esto.) Justamente, un problema que suscitan los dilemas es poner en cuestión el carácter vinculante de la moral para estos casos. Una manera de reconciliar dicho carácter vinculante, y a la vez aceptar el fenómeno de los dilemas, es presuponiendo el deber de los agentes, o la necesidad derivable de un concepto de agente virtuoso, de sentir cierto estado pertinente al caso. De este modo, el agente muestra deferencia por la alternativa que dejó a un lado y, en tal sentido, ésta se vuelve "indirectamente vinculante". Este carácter "indirectamente vinculante" suele atestiguarse mediante categorías tales como la de "compensación". Un agente que ha tomado una decisión trágica puede que tenga que compensar a los que han resultado afectados por su decisión; sin embargo, uso el giro "puede que..." para sugerir que depende tanto de la evaluación del acto en cuestión como del estudio profundo de una categoría filosófica como la de compensación, que no es nada inocente porque, entre otras cosas, podría suponer que, ante la "pérdida de ciertos bienes considerados intrínsecamente valiosos", tales bienes pueden ser "reemplazados" sin más, es decir, compensados por otro bien. Esto parece poner el asunto como si se tratase la moral de un tema de supermercado: si pierdo un bien lo cambio por otro que se encuentre en alguna góndola. Así pues, parece que aceptamos que los bienes se rigen por unidades de medición comparables y son reemplazables o compensables siempre. Un mundo así podría perder su ribete trágico del siguiente modo: perderíamos el sentido de nuestra vulnerabilidad ante aspectos del mundo desgraciados que se nos imponen y determinan la pérdida de bienes si cada vez que perdemos un bien obtenemos un reemplazo que, además, debe resultar "comparable", lo cual da por sentado el punto problemático de que haya dilemas con alternativas no comparables tal como sugiero en el texto. El otro gran problema es qué compensación podemos esperar, si cabe tal cosa, de agentes que han sido forzados a producir daños por circunstancias externas del mundo que son coactivas. (Véase Williams 2006; también Scheler 1961, pp. 162 y 167-168, que sostiene la imposibilidad de localizar la culpa en estos casos y arguye que el agente es "víctima de su culpa" o ha "caído en culpa", como ocurre en Edipo en Colono, cuyo protagonista sostiene que él ha "padecido lo que le ha ocurrido"; con referencia a esto véase Williams 2006, p. 191.) Véase una discusión específica de distintas teorías sobre el residuo en Greenspan 1995, especialmente en los capítulos 4 y 5 . Una discusión más específica sobre el alcance que Williams le da al residuo

Diánoia, vol. LV, no. 64 (mayo 2010). 
to, ya que cada requerimiento es adoptado con una forma absoluta. Por ejemplo, volviendo al caso de Sofía, la decisión en favor de uno de sus hijos no se explicaría adecuadamente bajo la idea de balance, diciendo, por ejemplo, que tiene más fuerza salvar al hijo que tiene más capacidad de sobrevivencia en las barracas que el otro. Articular el balance dando fuerza a la mencionada propiedad moral sería contraintuitivo porque sugeriría que la capacidad de sobrevivencia es una propiedad moral relevante, lo cual parece muy discutible.

Ahora bien, muchas veces el sacrificio se considera graduable. Cuando se introduce la idea de que hay una graduación en el sacrificio, se está introduciendo la posibilidad del balance y la comparación: un requerimiento es más fuerte que el otro, más significativo, menos trivial, etc. En consecuencia, los requerimientos son susceptibles de enfocarse a partir de la posibilidad de que uno "derrote" al otro. Esta observación me conduce a examinar los dilemas que involucran requerimientos prima facie.

\section{Los dilemas con requerimientos prima facie y el problema de su solución racional}

En la sección anterior mostré cuál era la idea que estaba detrás de la afirmación según la cual hay dilemas morales irresolubles. Algunos filósofos (Sinnott-Armstrong 1988, pp. 53-71) aceptan que estos dilemas morales son posibles, mientras otros prueban diversas clases de argumentos para rechazar esta conclusión. Por ejemplo, argumentan que las situaciones de inconmensurabilidad existentes son débiles y no fuertes (sobre esta distinción, cfr. Zucca 2007, p. 85), en el sentido de que, haciendo un esfuerzo adicional al ordinario, un agente o varios agentes encontrarían un metacriterio de solución racional. De este modo, la inconmensurabilidad o la simetría se vuelven problemas epistémicos, más que ontológicos, y además a la larga se tornan problemas resolubles. Aunque me parece que este argumento en ocasiones puede funcionar, su rendimiento no es el que esperan los enemigos de la posibilidad de estos tipos de dilema. Pienso que hay situaciones genuinas de inconmensurabilidad o simetría en la moral donde no es necesario que el

moral se encuentra en Bagnoli 2000. De la lectura e intercambios informales que sostuve con Bagnoli logré captar que su diferencia con Williams es más bien de acento. Mientras Williams pone mucho énfasis en los aspectos externos trágicos del mundo, Bagnoli quiere reservar cierta significatividad en el residuo con independencia de estos aspectos trágicos, y en esto su tesis está cercana a la tesis intermedia (con claves en ética de la virtud) que defiende Greenspan en el libro ya citado.

Diánoia, vol. LV, no. 64 (mayo 2010). 
agente tenga que saber algo más. Por ejemplo, éste es el caso de Sofía. Ella no tiene necesariamente que mejorar su información. Su dilema es auténtico en sentido ontológico y no epistémico (véase una distinción de estos dos sentidos en McConnell 2002, p. 13), es decir, no es un dilema moral $^{17}$ que se resuelva dependiendo de una mejora del conocimiento empírico y moral de Sofía, sino que se trata de un estado externo coac-

${ }^{17}$ Con argumentos algo diferentes, tanto Nora Rabotnikof como Pablo Muchnick enfatizaron el carácter trágico de este caso apuntando al hecho de que se trata de un acontecimiento externo que se le impone a Sofía y también a Agamenón. En ambos casos se trata de agentes morales ligados por vínculos inmediatos y poderosos: los de ser padres (en un caso, madre de dos hijos; en el otro, padre de una hija). Rabotnikof dijo que quizá una madre obraría - debería obrar, sugirió- de otro modo. A tono con la inquietud de Rabotnikof, se me ocurre que, en vez de tener que "elegir" cuál hijo debe salvarse de la cámara de gas, Sofía tendría otros dos caminos: i) matar ella a sus hijas y luego matarse; ii) no matar ella a sus hijas y directamente suicidarse (varios éticos de inspiración aristotélica hablan de "autosacrificio" cuando ya nada moralmente aceptable parece posible). La primera posibilidad se parece mucho al primer ejemplo en la literatura trágica de reivindicaciones feministas: me refiero a la Medea de Eurípides, que mata a sus hijos y se suicida antes que sus enemigos (los aliados de Poliméstor, que ha asesinado a su hijo Polidoro) tomen represalias. La idea de Rabotnikof tiene cierto aire de familia con lo que quizá diría una ética del cuidado; empero, mi pregunta para Rabotnikof es ¿qué guía segura, si la hay, daría una ética del cuidado en este caso? ¿Le dirían a Sofía que salve a la niña y no al niño, dado que en el primer caso comparten género? No parece ser fácil este terreno para la ética del cuidado ni para ninguna teoría moral. (Un análisis de dicha teoría puede verse en Rachels 2007, pp. 245-263). Es verdad que la ética del cuidado atiende en la solución de conflictos morales a los lazos más "inmediatos", algo que tiene sintonía, a su vez, con la ética de la virtud, si recordamos que para Aristóteles las relaciones afectivas (de amor a la pareja, a los hijos) eran singulares, irrepetibles e irremplazables (Nussbaum 2005, p. 144). El problema en el caso de Sofía es que estos "lazos inmediatos" en principio estarían constituidos por ambos hijos, si es que desde un punto de vista "imparcial" consideramos que ambos tienen el "mismo valor moral", salvo que la ética del cuidado rompiese con este juicio y prefiriera otro que aprobase elegir en condiciones de cercanía afectiva con uno de los hijos, por ejemplo, por compartir con él el mismo género. Sea como fuere, hay que reparar que, en cualquiera de los casos (que Sofía decida cuál hijo se salva de la cámara de gas, que ella los mate y se suicide o que se suicide dejando la decisión sobre la suerte de sus hijos al nazi) la alternativa que se elija será trágica debido a la combinación de aspectos que se le imponen a Sofía y que ella no puede controlar completamente, y el resultado es funesto y destructivo siempre, en cualquiera de las tres alternativas. El caso quizá menos funesto, aunque resulte algo chocante señalarlo, es que Sofía siga el dictamen del nazi, pues así se salvaría uno de sus hijos, lo cual significaría optar por algo así como un pretendido mal menor. Aunque de inmediato hay que agregar que el mal sigue siendo mal aunque sea "menor", a menos que se demuestre que tal mal ha sido genuinamente eliminado o evaporado.

Diánoia, vol. LV, no. 64 (mayo 2010). 
tivo del mundo que se le impone y, por lo tanto, es objetivo (Blackburn 1996, p. 127) con respecto a ella. Lo que sí creo es que resulta inconveniente restringir el análisis admitiendo sólo que los dilemas morales "auténticos" son los que se articulan en los términos que he explicado. Mi tesis es que, incluso cuando se pueda establecer que un agente

A Rabotnikof le surge la duda, además, de si este caso es un caso genuino de dilema "moral". Su duda radica en que si por moral entendemos la elección de una voluntad "libre" en el marco de alternativas contrapuestas, entonces el caso de Sofía debería quedar fuera de mi análisis: es trágico, pero no es un dilema moral. Me parece una duda interesante, pero discrepo de su rigidez conceptual implícita en lo que atañe al entendimiento de la moralidad. En primer lugar, quitando estos casos trágicos extremos que envuelven coacción externa del tipo que fuera (podría pensarse también en casos de estado de necesidad como los de los "exploradores de caverna" de Fuller 1989, o la tabla de Carnéades o La Balsa de la Medusa), en general —a excepción de casos trágicos como los que examino-, la filosofía moral tiene una postura determinista en términos causales, pero a la vez compatibilista con la posibilidad de responsabilización (acerca de esta discusión, véase el trabajo clásico de Strawson (1974); un interesante estudio del problema, defendiendo una tesis compatibilista que cuaja con diversos tipos de determinismo, menos uno fatalista o trascendente, se encuentra en Salles 2006). En segundo lugar, y más tratándose de casos dilemáticos, conviene poner a prueba las "abstracciones filosóficas", esto es, las caracterizaciones de los mismos, con una mirada atenta en las peculiaridades de los casos en sí (una postura general en este sentido se encuentra en Platts 1999, p. 143). En tercer lugar, hay que separar el momento de la decisión del agente del momento de su evaluación en materia de responsabilidad, momento que en sí mismo es tan complejo que requiere muchos tipos de discriminaciones conceptuales considerando cada caso particular (véase Williams 2006). Respecto del momento de la decisión, hay varias alternativas; por ejemplo, un filósofo aristotélico podría decir que casos como los de Sofía son "mixtos", pues involucran elementos involuntarios (explicables por la coacción) y voluntarios (explicables por la decisión que efectivamente el agente adopta). Un autor como Bernard Williams (2006, p. 192, n. 43) ha sostenido que "En la perspectiva trágica, actuar, ser un agente, tiene un carácter doble. Por un lado, consiste en tomar consejo con uno mismo, sopesar los pros y los contras y hacer todo lo posible por prever el orden de los medios y los fines. Por el otro, se trata de hacer una apuesta sobre lo desconocido y lo incomprensible y tomar un riesgo sobre un terreno que sigue siendo impenetrable para nosotros. Esto implica entrar en el juego de las fuerzas sobrenaturales [...] en el que no se saben si éstas preparan para el éxito o el desastre." Por lo tanto, conforme a Williams, uno podría hablar de "moralidad" en la decisión sobre estos casos trágicos, pero de una "moralidad" con este carácter dual del que hablaba Aristóteles o del que habla Williams (citando a Vernant). No hay duda de que la moralidad excede, además, el momento de la decisión. Con posterioridad a ella se abre un abanico de posibilidades: en el caso de Sofía fue su suicidio posterior. Con todo, el tema de cómo quedará constituida o alterada la identidad moral —narrativa— de un agente que decidió en circunstancias coactivas trágicas es variopinto: mientras que Sofía se suicidó, otros como Heracles, luego de matar a sus hijos y a su esposa en un

Diánoia, vol. LV, no. 64 (mayo 2010). 
compara alternativas y hace lo que considera "lo mejor posible", ello no elimina el hecho de que este agente enfrentaba un auténtico dilema moral. Por ejemplo, pensemos en el caso de Agamenón. Supongamos que Agamenón "hizo lo mejor posible" sobre la base de que pudo "comparar" su requerimiento como militar y estadista de invadir Troya y su requerimiento como padre de Ifigenia. Decide que lo mejor es matar a Ifigenia. Supóngase que la base de su comparación es "cardinal": tiene mejores resultados agregados invadir Troya que salvar la vida de un individuo; en este caso, su hija. ¿Diríamos que esta solución eliminó el hecho de que Agamenón enfrentaba un auténtico dilema moral? Varias intuiciones aconsejarían no ofrecer una respuesta positiva para esta pregunta. Se podría argüir, por ejemplo, que un individuo cuenta tanto como un conglomerado de personas, o que un individuo no es intercambiable con un conglomerado de personas. El argumento de que un individuo "no es intercambiable" con otro (como en el caso de los hijos de Sofía) o de que un individuo (por ejemplo, Ifigenia) no es intercambiable con un conglomerado de personas (el ejército griego comandado por Agamenón) es relevante por dos razones. La primera es que tiende un manto de sospecha sobre si invadir Troya es la "mejor solución". La segunda es que cuestiona las bases mismas de "mejor solución". Sugiere que este dilema quizá sea uno en el que las alternativas son genuinamente incomparables, y que apelar a la comparación —en este caso, en vena cardinal- es un error conceptual.

Ahora bien, cuando se sostiene que un agente "resolvió" su conflicto comparando, sin duda se está diciendo que en cierto sentido lo ha resuelto racionalmente, y la fuerza de este tipo de racionalidad emana de la comparabilidad subyacente de alternativas (Chang 1997, p. 3). Además, cuando el agente compara se está presuponiendo que su "método" de resolución ha articulado alguna forma de balance o ponderación a fin de establecer que un requerimiento tiene más fuerza, peso o importancia moral que el otro. Cuando un agente está articulando un balance,

estado de locura, y estando a punto de suicidarse por ese hecho, es persuadido por Teseo de no hacer tal cosa; cuando Heracles escucha a Teseo ya está "saliendo de la tragedia" (Williams 2006, p. 198). En cambio, Áyax, tras hacer lo que hizo, no pudo soportar "la imagen que los otros se hacían de él"; su autoestima, basada en el honor, había sido destruida y por este hecho se suicida (Wiliams 2006, p. 197). Finalmente, el momento de la evaluación de responsabilidad de un agente apremiado por circunstancias trágicas es en sí mismo un tema para un trabajo independiente: la tesis general según la cual no es posible responsabilizar a agentes por circunstancias trágicas es un lugar común que sin duda requiere muchas cualificaciones, atendiendo tanto a la teoría moral como a la legal cuando el Estado debe intervenir también en esta evaluación. 
lo que tácitamente está haciendo es tratar ambos requerimientos como prima facie y no como no derrotables. Entre requerimientos prima facie es posible pensar que un requerimiento, por medio de un balance, derrota al otro. Sea como fuere, aquí hay dos ideas que, tratadas con displicencia, pueden generar dos confusiones, haciendo pensar que estos dilemas son meramente aparentes y no posiblemente auténticos. La primera confusión es asumir que, porque hay comparación y balance, y, por lo tanto, hay cierto sentido de racionalidad en la solución, tal dilema no es auténtico sino aparente. La segunda es asumir que, como los requerimientos son tratados como prima facie, de nuevo estos dilemas son meramente aparentes. Aunque ambas confusiones de algún modo están ligadas, voy a tratarlas en forma independiente.

Primera confusión. Es verdad que, si hay un balance comparativo, existe cierta "racionalidad" en la solución a un dilema. Veamos: el balance conduce a determinar que un requerimiento tiene más importancia que el otro. Por ejemplo, Platón podría pensar que tiene más fuerza el deber de proteger al amigo de un probable daño que el deber de devolverle el arma. Ahora bien, cuando estamos articulando un balance, estamos asumiendo implícitamente una idea de sacrificio graduable. Estamos diciendo que un requerimiento pesa "más" que el otro, en cuyo caso el requerimiento "sacrificado" era "menos importante" o "menos significativo", etcétera.

La relación de "más peso", cualitativa o cuantitativamente graduable, puede pensarse en una paleta de distintas posibilidades de intensidad o relevancia. Así, puede haber un requerimiento que tenga muchísima fuerza sobre el otro, mucha fuerza, un poco más de fuerza, ${ }^{18}$ etc. Al intentar explicar esta relación surgen tres problemas que presentaré de un modo muy general. Aunque la presentación podría refinarse muchísimo, mi idea es hacer una presentación general a fin de mostrar no tanto los problemas en sí, sino cómo estos problemas son atendibles a la hora de meditar en cuán racional es la solución a los dilemas mediante un balance.

El primer problema es cómo tener un método confiable - y si es posible tenerlo- que permita establecer estos grados de fuerza. No existe acuerdo en filosofía moral y política al respecto. Mientras algunos sostienen que este método es el de una medición cardinal donde un valor tiene un peso cuantitativo determinado; ${ }^{19}$ otros piensan que, en materia moral, este método es inaplicable, porque los requerimientos tienen

${ }^{18}$ Un intento - muy discutido- por identificar pautas objetivas para establecer estas intensidades ha sido desarrollado por Alexy (2002).

19 Típicamente, los utilitaristas. Hay discusión sobre si el utilitarismo declara 
propiedades de fuerza cualitativas que, de ser traducidas a magnitudes cuantitativas, perderían su significado. ${ }^{20}$ Además de esta disputa metodológica, existe la sospecha de que, incluso si hubiera casos claros en los que puedan establecerse las intensidades de los requerimientos, habría muchos casos nada claros. Por ejemplo, a veces podríamos establecer si una promesa es "insignificante" de tal modo que no esté prohibido incumplirla y sea posible cumplir con otro deber: por ejemplo, auxiliar a un hombre atropellado en la calle. Pero puede haber diversos tipos de desacuerdo en otros casos, e incluso en el caso del ejemplo del atropellado, acerca del "grado" de significación de un requerimiento normativo y de otro. ${ }^{21}$ Esto es todavía más claro en la discusión sobre el aborto. Mientras que para ciertos liberales abortar, al menos dentro de los tres primeros meses de embarazo, sería un "mal menor", ${ }^{22}$ para ciertos católicos sería un mal "mayor".

El segundo problema se vincula directamente con la naturaleza misma del balance. En primer lugar, existe mucho desacuerdo en metaética y filosofía del derecho acerca de cómo explicar la "fuente de objetividad" del balance (Maniaci 2004). ¿En qué fuente aceptable descansa la idea de que un requerimiento tiene más fuerza que el otro? Diversas respuestas se han dado, pero ninguna ha logrado erradicar cierto escepticismo. Por ejemplo, para cierta versión que hunde sus raíces en ideas del estilo de las sostenidas por David Ross, el balance no depende de un conjunto de principios de ordenación independientes de un agente;

resolubles todos los dilemas siempre. En este sentido, véase Railton 1996, y Kooi y Tamminga 2008.

${ }^{20}$ Por ejemplo, si quisiéramos analizar el valor "honestidad" en términos de "ganancias y pérdidas", el argumento es que estaríamos perdiendo el significado de honestidad al traducirla a términos cardinales o cuantitativos. Stricto sensu, es un argumento de aire kantiano que prohibiría confundir el tipo de valor deontológico de ciertos conceptos normativos con un valor utilitario o un "precio".

${ }^{21}$ Por ejemplo, supóngase la promesa de un padre a su hija de visitarla en Estados Unidos, donde ella vive, y que la haya hecho muy vivamente porque hace cuatro años que no la ve. Camino a tomar su vuelo se encuentra con el hombre atropellado. Si se detiene lo auxiliará, pero perderá el vuelo y no habrá otro hasta el mes siguiente. Alguien podría decir que nuestros deberes morales más fuertes son con los próximos y no con los más lejanos, o podría decir que son más fuertes los deberes que asumimos primero en el tiempo, etc. Es decir, no es descabellado discrepar sobre la importancia de la promesa y el deber de dar auxilio, incluso cuando a un grupo de personas nos parecería más intuitivo que la promesa pierda importancia en este caso.

${ }^{22}$ Pongamos por caso a Margarita Valdés (2001, pp. 8-9), quien sostiene que el aborto no es para un liberal algo "deseable en sí mismo", sino un "mal menor" frente a la perspectiva de tener un hijo no deseado.

Diánoia, vol. LV, no. 64 (mayo 2010). 
más bien depende de un agente ideal que puede ver qué propiedades "salientes" del caso inclinan la balanza en uno u otro sentido. McDowell (1998), por ejemplo, sostiene que "él no niega que existan dilemas genuinos", pero luego agrega que, si hubiera una respuesta correcta ${ }^{23}$ para un dilema, un agente virtuoso sería capaz de "verla". ${ }^{24}$ No resulta obvio todavía si la idea de observadores ideales o agentes virtuosos es factible y en qué medida lo sería. A excepción de éticas como las de la virtud, tampoco es posible convencer a todos los filósofos de que sea realmente este "ojo sabio" 25 el que vea cuál es la solución correcta para el caso. Y tampoco está claro si un hombre virtuoso por definición debería resolver correctamente un dilema; esta afirmación es muy atractiva porque se supone que justamente la definición de virtuoso supone que él siempre tiene acceso a respuestas correctas. Empero, un virtuoso podría tener el conocimiento más fino del mundo y del contexto particular del dilema y pese a ello enfrentar un auténtico dilema del que él no es el responsable causal. ${ }^{26}$ Este problema no es otro que el de la "suerte moral" (Nussbaum 1986, p. 3). Piénsese en aquel súbdito al que un tirano fuerza a hacer algo moralmente reprochable, bajo la amenaza de perder a su familia (Aristóteles 2005, p. 94). Supóngase, por mor del argumento, que el súbdito es virtuoso y determina que la respuesta

${ }^{23}$ Por lo general, esta "respuesta correcta" consiste en identificar un camino entre los cuernos del dilema que permita satisfacer ambas virtudes en forma coherente, de modo tal que no se rubrique una incoherencia y se acepte que a veces nuestras virtudes pueden mantener un conflicto genuino en el cual se ponga en jaque su presunta unidad. Sobre esta línea véanse, por ejemplo, Zagzebski 1996, que defiende un fuerte correlato entre virtudes epistémicas y virtudes morales con primacía de las primeras, en particular de la phrónesis como metavirtud para ordenar coherentemente virtudes que pudieran entrar en conflicto en algún caso; Hursthouse 2001, que defiende una versión dura de la ética de la virtud según la cual el virtuoso siempre puede encontrar la respuesta correcta, y si no fuera posible dado el carácter trágico del mundo, este agente mostrará pena pues así es, por definición, como actúa un genuino virtuoso; y Sollum y Farrelly 2008, que compilan discusiones sobre la aplicación de las virtudes al campo legal; también para esta última línea, cfr. Amaya 2008.

${ }^{24}$ Con lo cual la primera premisa de su argumento (proclive a aceptar dilemas) sería borrada con la segunda premisa del argumento (que un virtuoso vería cuál es la respuesta correcta).

${ }^{25}$ Este ojo sabio depende de la articulación de la phrónesis o discernimiento práctico. Véase Nussbaum 2005, especialmente las pp. 113-202; Zagal 2006, y Santiago y Trueba Atienza 2006, pp. 89-102.

${ }^{26}$ Como sí lo sería si, por ejemplo, prometiera matrimonio a varias mujeres a la vez. La encerrona no radicaría necesariamente en una inconsistencia del sistema normativo pertinente, sino en un dilema que el propio agente se ha generado. 
correcta es decirle al tirano: "Sigue adelante, pero no lo haré porque mi genuina y única obligación moral es hacer lo correcto." Aquí lo correcto sería "evitar ensuciarse las manos"; sin embargo, la consecuencia fatal es la muerte segura de la familia y/o el propio "autosacrificio" del súbdito. En este tipo de dilemas suele aparecer el predicado "trágico" para caracterizarlos. No se trata sólo -o necesariamente-de requerimientos que puedan ser inconmensurables o simétricos, ${ }^{27}$ sino casos donde un agente enfrenta aspectos del mundo que lo fuerzan ${ }^{28}$ de tal modo que, cualquier cosa que haga, habrá hecho algo muy malo. ${ }^{29}$ Aquí también suele aparecer otra idea de "irresoluble" para calificar estas situaciones que puede combinarse con el otro sentido de irresoluble, esto es, con la falta de criterio, escala o procedimiento plausible para establecer cuál es el requerimiento que ha de seguirse. Este sentido está ligado con la idea de una elección "trágica" (Barry 1984), es decir, entre males: entre la vida y la muerte, donde haga lo que haga el agente no habrá podido evitar hacer algo muy malo, ${ }^{30}$ destruir o sacrificar bienes valio-

${ }^{27}$ De hecho puede haber dilemas, por ejemplo, con alternativas inconmensurables (digamos, acerca de si comprar un cuadro de Matisse o una limusina), pero estas alternativas no entrañan situaciones de necesaria relevancia moral o carácter "trágico": incluso podría haber dilemas así que permanezcan sin solución, pero esto no los convierte en morales y menos todavía en trágicos. Estoy de acuerdo en esto con una sugerencia del árbitro que redactó su informe en inglés.

${ }^{28}$ Entre quienes sostienen que son extravagantes (!) o forzados (!) los ejemplos de dilemas donde los agentes se ven coaccionados o forzados por circunstancias externas que no pueden dominar, se encuentra Mothersill 1996, pp. 66-84. Incluyo los signos de admiración para poner en evidencia mi inconformidad con esta idea: basta con observar con sensibilidad el mundo para detectar la existencia pasada, presente e inevitablemente futura de conflictos trágicos.

${ }^{29}$ A diferencia del comportamiento lógico de la inconmensurabilidad y la simetría, el elemento trágico tiene un carácter bifronte: a veces lo vemos "absoluto" y no graduable; otras veces lo vemos "graduable" y hablamos de distintas intensidades de males involucrados en una decisión.

${ }^{30}$ Precisando todavía más la cuestión que con buen tino me recordara el árbitro del informe en español, la cuestión de qué involucra el "fenómeno de lo trágico" tiene en la literatura aspectos muy variados y complejos que se resumen en la idea de "final no feliz". Entre estos aspectos suelen figurar ideas como las siguientes: i) que los agentes enfrentan situaciones "inesperadas" en el sentido de que se trata de eventos impuestos al agente por el azar o la suerte moral con resultados que él no podía prever o, si previó, no pudo dominar; ii) que sea cual fuere la elección que haga, no podrá escapar o evitar, cuando menos para el tiempo t en que enfrenta el conflicto, que se produzca un mal que entraña el sacrificio de algo valioso y la destrucción necesaria, por lo tanto, de una alternativa exigible. La aclaración que hago del tiempo se vincula a que los conflictos pueden ser enfocados desde dos puntos de vista temporales diferentes: sincrónico y diacrónico. Quizá un mal te- 
sos, etc. Frente a esto, se ha aducido que el súbdito no enfrenta un dilema trágico, ya que al existir sólo una obligación moral se simplifica el panorama. ¿No tiene el súbdito obligaciones con su familia? Incluso en la hipótesis de la tiranía, ¿tiene el súbdito alguna obligación con el soberano? Estas preguntas sugieren que está pendiente de articulación una teoría que demuestre cómo se ordenan adecuadamente nuestras múltiples obligaciones morales y legales (Waldron 1993, p. 203).

El tercer problema es el de la "precariedad" y "contextualidad" del balance. Las soluciones para los dilemas parecen requerir mayor atención en las peculiaridades del caso; pero surgen dos preguntas generales. La primera es si esta solución para el caso particular podría usarse

rrible producido en un momento determinado, o en tiempos sucesivos (pensemos, por ejemplo, en la Orestíada) podría evitarse, dadas ciertas condiciones interpuestas luego de nuestro aprendizaje de conflictos trágicos pasados (Barcan 1987, p. 188). Empero, estas condiciones no evitarían nuevos conflictos trágicos; tampoco resultaría imposible que la búsqueda de solución de ciertas tragedias generase más tragedia o que ciertas tragedias, por hipótesis, no pudieran resolverse satisfactoriamente nunca, por ejemplo, de un modo que convenza a todas las partes ilustradas y contendientes de un conflicto. Ahora bien, cuando se extrapola este fenómeno trágico al ámbito de grandes conflictos sociales, sus efectos podrían ser potencial o actualmente disruptivos de la estabilidad social, del mismo modo que muchos eventos trágicos ponen en cuestión la identidad y unidad de los agentes morales en cuanto que son situaciones para las cuales su bagaje moral no estaba preparado para aceptar o resolver. Como se sabe, los filósofos han sostenido posturas distintas con respecto a estos eventos. Mientras autores como Isaiah Berlin o Bernard Williams los aceptan como tales, otros los niegan de distintos modos. En el libro X de la República, Platón expulsa a los poetas trágicos por poner a la polis en un desorden potencialmente destructivo. En su obra ética, Aristóteles sólo admitía que lo trágico sea producto de hamartía (error trágico) o hybris (desmesura o imprudencia). Sobre esto último, véase Trueba Atienza 2004. Otros autores, como Hegel, apostaban a que, en un Estado racional de derecho, los conflictos trágicos iban a ser eliminados (sobre Hegel, véase Beistegui y Sparks 2000, especialmente las pp. 11-37). Señalando los aspectos que indico en i) y ii) se encuentra el imperdible trabajo de Scheler 1961, pp. 143-169; Steiner (2001, pp. 12-13) muestra estas mismas características, pero extraídas de la literatura trágica. Algo más clásico es el trabajo de Sewall (1959). Para un examen psicoanalítico esclarecedor de lo trágico, véase Alford 1992, capítulo 1. Contrastando el modelo trágico clásico y la polis de Pericles con los conflictos en torno al proyecto ilustrado entre Habermas y Foucault, se halla Rocco 2000. Por supuesto, para una importante inspección filosófica global de lo trágico, cfr. Nussbaum 1986. Para una exploración de lo trágico en el ámbito político con sugestivas relaciones entre Maquiavelo y el Hamlet de Shakespeare, véase Rinesi 2003. Finalmente, para explorar diversos sentidos de lo trágico (como los que retrato en i) y ii) en la moral, pero principalmente en el ámbito del derecho constitucional, véanse, por ejemplo, Zucca 2007; Alexander 1998, pp. 115-119; Balkin 1998, y Post 1998.

Diánoia, vol. LV, no. 64 (mayo 2010). 
como patrón para solucionar casos futuros "semejantes". La segunda es si esta solución, que atiende al contexto del caso, puede ser "estable" a lo largo del tiempo o si podría ser desafiada bajo una nueva interpretación de la fuerza de las propiedades del caso o introducir nuevas propiedades que alteren la relación de fuerza primigenia. En el fondo de estas dos preguntas subyace alguna forma de particularismo moral (Hooker y Little 2000).

La presentación general de estos tres problemas sugiere que cuando decimos que la solución a los dilemas es factible mediante un balance, no estamos articulando la idea de la omnipotencia de la razón para resolver dilemas, sino más bien la idea de los límites de la razón. Solucionar conflictos dilemáticos mediante el balance ya supone asumir alguna forma de limitación de la razón que exige más humildad que prepotencia. Esta limitación tiene un carácter bifronte. En primer lugar, la limitación surge de la controversia en torno al mismo método de solución: el balance. En segundo lugar, la limitación surge del hecho de que la decisión de un dilema deja un residuo normativo que, a diferencia de los casos de inconmensurabilidad y simetría, es "graduable". Precisamente por este doble orden de dificultades se han buscado otras alternativas; por ejemplo, ciertos autores propugnan olvidar el balance y establecer, de acuerdo con "ciertas circunstancias", "reglas de prioridad" acerca de cómo resolver estos conflictos. Éste es el caso de Lorenzo Zucca (2007, p. 141), y también el de David Martínez Zorrilla (2007 pp. 202 y ss., y 376), que sostiene que es menester utilizar en estos conflictos reglas de prioridad "claras". Aunque los autores mencionados están pensando en criterios de prioridad para dilemas constitucionales, y no exactamente para dilemas morales, pienso que sus reflexiones son útiles para mi presente argumentación. ${ }^{31}$ Ambos autores concuerdan en

${ }^{31}$ No excluyo que mi analogía entre dilemas morales y constitucionales exija hacer diferencias, como sugiere correctamente el árbitro que hizo su informe en inglés. Precisamente, la operación del recurso a la analogía convive tanto con semejanzas como con diferencias relevantes. Una de estas diferencias es que, como podría alegar un filósofo perspicaz como mi árbitro, las "fuentes de autoridad" de la moralidad y el derecho son diferentes o, al menos, susceptibles de algún nivel relevante de distinción. No obstante, en seguida este mismo filósofo podría reconocer que este punto es muy discutible. Pienso que este reconocimiento podría surgir del hecho de que las relaciones entre el derecho y la moral están lejos de ser todo lo claras que desearíamos, sobre todo del lado del derecho, cuyo tipo de "autonomía" con respecto a la moral es todavía muy debatido por diversas corrientes de la filosofía del derecho (positivismo incluyente, iusnaturalismo, etc.). Con todo, mi apelación a una discusión sobre dilemas constitucionales es útil cuando aceptamos que hay dos semejanzas relevantes entre ambos tipos de dilemas. En primer lugar que, de 
que un "dilema constitucional" comparte todas las características posibles que he defendido en este texto, tanto cuando ofrecí un concepto general de dilema, como cuando presenté dos tipologías diferentes para comprenderlos.

Ahora bien, ante todo es preciso tener en cuenta el tipo de orden en el que los filósofos mencionados están pensando. No parece ser un orden lexicográfico de principios o reglas de prioridad como los que se han ensayado en filosofía moral al estilo de "tendrá más peso la obligación asumida primero", o cosas por el estilo (para una crítica a esta estrategia, Sinnott-Armstrong 1988, p. 63). Se trata de reglas de prioridad que deben surgir del mismo balance incoado en una situación concreta y no de un orden a priori. Aunque ambos autores dan por sentado el éxito de esta propuesta, me temo que, al igual que el balance, ésta enfrenta también problemas.

En primer lugar, no es verdad que las reglas de prioridad de este tipo sean muy diferentes del balance, como piensa Zucca. Estoy de acuerdo con Martínez en que: i) "balance" es un rótulo que sirve para dar cuenta de diversas operaciones; ii) que luego de sopesar las razones en pro y en contra de uno y otro requerimiento en conflicto, la tarea que sigue es producir una regla de prioridad en favor de uno de los requerimientos. Es decir, que la tarea de balancear y producir reglas de prioridad es parte de la misma historia y no dos cosas diferentes como piensa Zucca. Clarificado este punto, comienzan los problemas para ambos autores. El principal es que ellos dan por descontado que estas reglas funcionen para resolver dilemas. Pese a que ambos autores suministran diversos

modo semejante al derecho, también en la moral o en la política se han urdido criterios de prioridad. Pensemos en la ordenación lexicográfica de bienes que hace Rawls o en la propuesta de criterios de temporalidad e importancia para ordenar promesas conflictivas hechas en el ámbito de lo privado. En segundo lugar, que los dilemas "constitucionales" son una especie de eslabón que conecta de un modo especial a la moralidad y el derecho: valores constitucionales como la libertad, la igualdad, la dignidad, la solidaridad, etc., tienen estirpe moral y esta moralidad define el núcleo de lo que cuenta como un valor al que luego un legislador constitucional le asigna el carácter de positivo y lo atrinchera mediante una técnica de formular normas legales abstractas de prohibición, permisión, obligación o facultamiento tal como pretenden funcionar, en rigor, los llamados principios constitucionales. Por último, deseo señalar que muchos dilemas constitucionales trágicos muestran la indeterminación del material jurídico para resolverlos: esto es típico en casos como la eutanasia, donde los jueces suelen pedir auxilio directamente a la moral. Esta petición de auxilio es algo ingenuo si se piensa que la moralidad o las teorías morales también podrían estar indeterminadas para estos casos por: a) no tener respuesta; b) ofrecer varias respuestas competentes pero discordantes; c) postular respuestas vagas para el caso en cuestión, etcétera.

Diánoia, vol. LV, no. 64 (mayo 2010). 
ejemplos de dilemas, no parecen reparar en el hecho de que establecer estas reglas puede resultar una tarea o bien imposible o bien muy problemática. Pensemos, por ejemplo, en un caso de dilema —qua simetríacomo el de los siameses que hay que separar porque, de no hacerlo, ambos morirán. Hay que decidir cuál de los dos vivirá y, en consecuencia, cuál morirá. ¿De qué modo aquí sería posible establecer una regla "clara" de prioridad para este caso? Suponiendo que no existiera en el discurso moral un metacriterio para desempatar, ${ }^{32}$ éste sería un caso que Martínez Zorrilla llamaría de "indeterminación" de la respuesta correcta. Entonces, ¿sobre qué base se fundamentarían estas reglas? En la posición de Martínez Zorrilla, la producción de reglas claras parece semejar un acto de estipulación; un acto en cierto sentido arbitrario. Si la semejanza es válida, entonces sus reglas claras de prioridad parecen más bien el producto de una elección arbitraria. Dicho de otro modo, la fuente de sus reglas de prioridad dependería de lo que llamé una elección radical, o de una moneda tirada al aire, ${ }^{33} \mathrm{o}$, en relación con

${ }^{32}$ Respondiendo a Jorge Ladrón de Guevara, sostengo que es verdad que en estos casos suele haber un metacriterio que se emplea para desempatar vinculado a la idea de "mayor capacidad física de sobrevivencia" como plataforma para el desarrollo moral de un futuro plan de vida. En caso de que este metacriterio pudiera aplicarse a algunos casos de siameses, ello no expurga su posible conflicto trágico. Zucca (2007, p. 151) comenta un caso de hermanas siamesas en el que los jueces, antes de aplicar el referido metacriterio, hicieron consideraciones acerca de qué constituye la "normalidad" y la "anormalidad" corporal, sosteniendo que el caso de los siameses es un ejemplo de la última. La normalidad viene definida para estos jueces como "integridad corporal". Ellos develaron parte del lado trágico de su caso de las siamesas cuando, al fundamentar su decisión en el mencionado metacriterio, no pudieron dejar de reconocer que estaban atados a no poder evitar sacrificar a una de ellas (se llamaban Jodie y Marie), y que la "sacrificada" "adquiriría su integridad corporal en la muerte", una integridad de la cual no podría ser obviamente consciente. Este razonamiento muestra no sólo el tipo de paradojas en que nos envuelve lo trágico, sino también su carácter inevitablemente sacrificial o malo.

${ }^{33}$ Sobre la estrategia de "randomización", coincido con Bagnoli (2006b) en que garantiza la "imparcialidad", pero no necesariamente otorga una justificación moral sustancial para resolver casos de "simetría" (podríamos añadir que tampoco casos de genuina inconmensurabilidad). Tal justificación debería apoyarse en un criterio sustancial que incluya ambas alternativas o las distintas instancias de un mismo principio. Además, no se trataría, según Bagnoli, de una solución significativa desde el punto de vista de una elección de la cual podamos ser declarados autores plenos y directos, ya que es un criterio aleatorio el que se emplea. Agradezco al árbitro del informe en inglés haberme recordado este excelente artículo de Carla Bagnoli, justamente acerca del cual tuve un breve intercambio informal con la autora después de haber presentado mi trabajo en Diánoia. 
el Derecho, del uso de discreción fuerte si es un juez el que tiene que determinar qué hacer en este caso.

A diferencia de Martínez Zorrilla, Zucca no habla de reglas "claras" de prioridad, sino de reglas que son "cualitativas", "contextuales" y "refutables". "Cualitativas" significa que estas reglas no se basan en un orden de medición cardinal de la fuerza de los requerimientos en conflicto; "contextuales" significa que hay que atender a las circunstancias particulares del caso, y "refutables" significa que el orden de prioridad otorgado a un requerimiento sobre el otro puede ser revisable en el futuro. ${ }^{34}$ Ante todo, estas tres características son parte del mismo balance con el que Zucca es beligerante y, en este sentido, reaparecen los tres problemas que presenté antes. Mientras la característica de ser un orden de prioridad cualitativo siembra dudas sobre qué tipo de respuesta objetiva es factible aquí, las otras dos características, contextualidad y refutabilidad, siembran dudas con respecto al pretendido "universalismo" de estas reglas de prioridad.

La objeción que los autores podrían hacerme es que, concediendo que sus reglas no funcionen con el éxito esperado para casos de simetría o inconmensurabilidad, sí podrían hacerlo para casos de conflicto entre requerimientos prima facie. Sin embargo, para estos casos aptos para un balance, resurgen los tres tipos de problemas sobre los que he llamado la atención; problemas que, en buena medida, explican el presunto rechazo de estos autores al balance; rechazo que en ellos, como he mostrado, no es real.

Segunda confusión. Cuando se sostiene que el conflicto moral se produce entre dos requerimientos normativos enfocados como prima facie, suele decirse que tal conflicto es por ello aparente. Esta estrategia ha sido usada a veces por cierta versión de la éticas deontologistas. Esto me parece un error que descansa en un uso ambiguo de la idea de prima facie (Sinnott-Armstrong 1998, pp. 97-102). Ante todo es menester distinguir dos sentidos diferentes de prima facie. ${ }^{35}$

${ }^{34}$ Esta característica salva a Zucca de caer en el monismo que intenta evitar cuando rechaza reglas "cuantitativas" de prioridad como las que proponen los utilitaristas. Además, el orden en que piensa Zucca no puede ser lexicográfico, en el cual un requerimiento siempre triunfe sobre el otro; esto es dinámico y está sujeto a revisión.

35 También destacando la importancia de la distinción que propondré, Williams (1993, p. 100) sostiene que la terminología de las obligaciones "a primera vista" es ambigua, ya que puede referir a una obligación que, tras un análisis adecuado, resulte "evaporada" o eliminada, o bien, que tras el análisis no resulte eliminada, sino que quede catalogada como menos fuerte; pero esta catalogación es compatible

Diánoia, vol. LV, no. 64 (mayo 2010). 
En primer lugar, prima facie supone algo así como una versión depreciada de "deber" que surge de su etimología latina. De acuerdo con su etimología, prima facie significa "a primera vista". No se trata de un auténtico deber, sino de un deber que a primera vista lo parece pero que, después de todo, podría no ser un deber. La idea es que si hubiera un conflicto de deberes al final, sólo uno de ellos sería el realmente aplicable, dado que el otro no era realmente un deber significativo. Sostengo que este sentido de deber presupone intuitivamente una suerte de "umbral", que a veces puede ser difuso, para definir qué cuenta como "insignificancia" de un deber, de modo que sea posible descartar la idea de que haya realmente dos deberes en conflicto. Este sentido de prima facie funciona muy bien con las llamadas promesas "triviales". Se supone que si la promesa es trivial, el deber que genera es un deber "a primera vista" que muy probablemente sea insignificante si se lo contrapone a otro deber que se reconstruye como significativo con algún grado. Este primer sentido es el que puede servir para mostrar que ciertos casos presuponen un dilema "aparente" o "falso", ya que el requerimiento en juego es uno y no dos: uno de ellos se asume como insignificante y es descartado del mapa del agente moral. Pero esto no se aplica al segundo sentido de prima facie.

El segundo sentido de prima facie supone algo distinto. No se trata de un deber insignificante, sino de un deber más débil que el otro deber. Respecto de este segundo sentido, lo que sostengo es que a veces podría haber problemas para determinar, en un presunto conflicto entre deberes, cuál de ellos cae "dentro" o "fuera" del umbral de insignificancia al que me he referido antes. Si un deber cae "fuera" del umbral ya es significativo y cuenta como un deber, aunque sea con una baja intensidad. En otras palabras: cuando cae fuera del umbral ello hace que sea un deber en este segundo sentido de prima facie y no ya prima facie en el primer sentido. Ahora bien, este segundo sentido deja todavía abierto el problema de cómo "graduar" confiablemente el rango de "debilidad" de un deber frente al otro. En este problema, en rigor, se encuentran compactados los tres problemas que presenté antes bajo la primera confusión. En pocas palabras: la debilidad de un deber frente a la fortaleza del otro admitiría una graduación que hay que establecer mediante un

con considerarla un "residuo" que incluso justifique imponer el deber de compensar a quien haya dejado a un lado tal obligación. También coincide en esta distinción Sinnott-Armstrong (1988, pp. 97-101) y defiende que ésta subyace en dos usos diferentes que David Ross hacía del término prima facie. Véase Ross 1987, pp. 83100. 
método en sí mismo controvertible. ${ }^{36}$ De cualquier manera, lo que intento decir es que este segundo sentido no erradicaría la existencia de un auténtico dilema, sino que podría presuponerla. Es la idea de que la solución de dilemas con requerimientos prima facie deja un "residuo" y por ello no puede contar como solución en sentido "pleno".

En todo caso, es probable que todavía haya que hacer una especificación más. Aun si estuviéramos dispuestos a llamar dilemas morales a aquellos en que para el agente es viable evitar el mal mayor y que, por este motivo, el requerimiento que conduce al mal menor tiene más fuerza que el otro requerimiento, parece que los dilemas más problemáticos son aquellos cuya solución deja un residuo especialmente significativo o intenso. Cuando el residuo supone un mal muy intenso que no puede evitarse sería posible, además, sostener que estos dilemas morales auténticos son trágicos.

\section{Conclusiones}

En este artículo he intentado mostrar cómo funciona la intuición según la cual en los dilemas morales, como formas cualificadas de conflicto moral, no es posible dar con una solución racional. He sostenido que esta tesis necesitaba ser precisada distinguiendo dos grandes grupos de dilemas que inciden en dos tipos distintos de desafíos a la manera de entender qué significa "solución racional", y si ésta es posible o no en los dilemas. Un primer grupo de dilemas está constituido por los que involucran requerimientos inconmensurables o simétri-

\footnotetext{
${ }^{36}$ Necesito hacer una aclaración adicional importante. Cuando se habla de prima facie en este segundo sentido no se elimina la posibilidad de pensar que la decisión del agente moral opere considerando todos los factores relevantes de la misma. Sin embargo, hay dos sentidos diferentes de la operación de considerar "todos los factores relevantes". Un sentido está ligado directamente a la idea de balance: un requerimiento triunfa sobre el otro. Este sentido es débil porque no elimina el requerimiento considerado más débil. El otro sentido, más fuerte, está ligado a la posibilidad de incoar una suerte de metarrequerimiento, tercera vía o valor comprehensivo que permita satisfacer, al menos parcialmente, los dos requerimientos en pugna. De algún modo, estos dos sentidos tienen un parecido de familia con la distinción que Ruth Chang (2004) hace entre una versión simple (la que llamo "débil") y una versión sofisticada (la que llamo "fuerte") de la operación consistente en contemplar "todos los factores relevantes" de una decisión. Por último, cabe subrayar que las expresiones "todos los factores relevantes" o "todas las cosas consideradas", son desprendimientos de la expresión inglesa "all things considered", que he omitido porque el árbitro que redactó su informe en español recomienda cierto purismo lingüístico fuerte en el uso del idioma español.
}

Diánoia, vol. LV, no. 64 (mayo 2010). 
cos no derrotables. Un segundo grupo de dilemas está constituido por los que involucran requerimientos prima facie, comparables y derrotables.

En el primer grupo de dilemas, la idea de imposibilidad de solución racional se explica, especialmente, aunque no exclusivamente, por la idea de "indeterminación" del discurso moral, esto es, por la ausencia de criterios, escalas o procedimientos racionales para solucionar el conflicto. La idea de que los dilemas, sea por inconmensurabilidad o por simetría, son irresolubles ha dado pábulo a la idea de que en estos casos queda sólo tirar la moneda u optar por hacer una elección radical, tomar salidas caprichosas, decisiones violentas, hacer uso de la discreción fuerte si se trata de jueces enfrentados a dilemas, etcétera.

Antes de repasar la característica del segundo grupo de dilemas, conviene recordar que también me he referido a los dilemas morales con componentes trágicos que suelen considerarse "irresolubles", pero en un sentido no agotado por la sola idea de indeterminación. Más bien, mi concepción predilecta hace hincapié en el elemento de sacrificio inescapable involucrado en las tragedias, y esto es relativamente independiente de si contamos con criterios para determinar qué alternativa podría tener, por ejemplo, más peso. Es necesario todavía un argumento ulterior que muestre que esta determinación de lo que quepa hacer ha eliminado por completo un sacrificio relevante, sea de rango graduable o no graduable. Es por este argumento que lo "trágico" es una especie de categoría "bisagra", ya que a veces lo trágico, combinado con la inconmensurabilidad o la simetría, no se considera graduable, y a veces sí cuando se combina con los dilemas del segundo grupo. En el segundo grupo, la idea no es tanto la de "imposibilidad" cuanto la de gran dificultad para establecer qué requerimiento debe primar sobre el otro. Se articula de este modo la idea de una solución apoyada en un método disputable: el balance. Mientras la decisión de los dilemas del primer grupo deja un residuo no graduable constituido por la alternativa sacrificada que en el fondo se concibe como absoluta, dado que ambos requerimientos son reputados como no derrotables, la decisión de los dilemas del segundo grupo deja un residuo graduable y, por lo tanto, el sacrificio involucrado también lo es.

A modo de resumen insistente: se podría decir que lo trágico podría envolver a la vez ambas categorías cada vez que se presenten cuando menos algunas de las características relevantes que he mencionado en este artículo: mal inevitable, sacrificio inescapable, destrucción de alternativas valiosas, etc., sólo que la diferencia de comportamiento de 
lo trágico estará atada al tipo de dilema en juego: esto es, si se trata del primero o del segundo grupo que esbocé en este trabajo. ${ }^{37}$

En cualquier caso, debo decir que el esbozo filosófico que he presentado sobre los dilemas y sus desafíos es parcial. La tarea de clarificación conceptual es importante pero no elimina, dickensianamente hablando, nuestras grandes esperanzas de lo que podría ocurrir si nos situáramos en el "revés de la trama" de la historia de los dilemas. He escogido como asunto medular de esta trama el centrarme en algunos de sus desafíos, pero el otro punto nodal en el que todavía me encuentro trabajando se vincula con reconstruir las diversas estrategias que los filósofos han urdido para enfrentar dilemas. La declaración de que un dilema pertenece al primero o al segundo grupo es materia de investigación concreta siempre y es independiente de estas caracterizaciones conceptuales dispuestas ex ante. Indagar en las múltiples estrategias que los filósofos han ideado para lidiar con dilemas y usar casos concretos como bancos de prueba para determinar si son dilemas solubles, disolubles o insolubles es una tarea estimulante. Examinar la plausibilidad de las propuestas filosóficas dedicadas a lidiar con dilemas me parece una actividad apasionante, pues es otra manera de hacer "chocar" las caracterizaciones brindadas en este trabajo con el afán de muchas teorías morales de no resignarse ante los desafíos de los dilemas. Espero haber contagiado al lector, aunque sea sólo un poco, mi entusiasmo por la relevancia teórica y práctica de considerar algunos de los desafíos de los dilemas e invitarlos a reflexionar sobre el otro lado del problema: cómo enfrentarlos o aceptar con resignación serena que a veces el resultado trágico será inescapable. Habrá que seguir meditando profundamente sobre esta vacilación pendular de los dilemas: de sus desafíos a nuestras (¿vanas?) esperanzas de enfrentarlos. Sería un alivio que los filósofos podamos decir algo en el futuro sobre si tiene sentido aferrarse a alguna de estas esperanzas para cuando adivinemos la cercanía de los tiempos difíciles o de los trágicos. ${ }^{*}$

${ }^{37}$ Tiene razón por esto el árbitro que hizo sus sugerencias en español al señalar que no se trata de una tercera categoría stricto sensu, sino que lo trágico puede estar presente en ambos grupos de dilemas, sólo que mi planteamiento - no cuestionado por este árbitro- es que el comportamiento conceptual varía si lo trágico puede considerarse como algo graduable o no.

*Este trabajo que, como dice uno de los árbitros de Diánoia, no es estrictamente exegético, fue escrito durante mi fecunda estancia de investigación posdoctoral en el Instituto de Investigaciones Filosóficas de la UNAM, en México. Lo expuse en el seminario de investigadores de dicho Instituto así como en la Academia Nacional de Ciencias de Buenos Aires. Mi intención, quizá, no fue tanto presentar tesis extraordinariamente originales sobre los dilemas, cuanto ofrecer a un auditorio filosófico 


\section{BIBLIOGRAFÍA}

Alexander, L., 1998, "Constitutional Tragedies and Giving Refuge to the Devil", en Eskridge y Levinson 1998, pp. 115-120.

Alexy, R., 2002, Theory of Constitutional Rights, trad. Julian Rivers, Oxford University Press, Oxford.

Alford, F., 1992, The Psychoanalityc Theory of Greek Tragedy, Yale University Press, New Haven/Londres.

Amaya, A., 2008, "The Role of Virtue in a Legal Justification", manuscrito inédito consultado por gentileza de la autora.

Anderson, E., 1997, "Practical Reason and Incommensurable Goods", en Chang 1997, pp. 90-109.

Aristóteles, 2005, Ética a Nicómaco, trad. José Luis Calvo Martínez, Alianza, Madrid.

más amplio que el de los filósofos morales un esquema con algunas de las implicaciones que hacen de los dilemas un tema no sólo fascinante desde el punto de vista teórico, sino acuciante desde el punto de vista de nuestras vidas. Hay pocas dudas acerca de que la cuestión de los dilemas morales es una de las más controversiales y debatidas en filosofía. Esto explica que los filósofos prácticamente tengamos disensos sobre cualquier punto central o marginal a nuestra discusión. Estoy profundamente agradecido, en primer lugar, por las cuidadosas, sutiles y ecuánimes recomendaciones conceptuales, bibliográficas y estilísticas de los dos árbitros anónimos. El hecho de que este texto haya sido mejorado sustancialmente le debe mucho a ambos, por lo que quizá sea algo injusto que quien figure como autor sea yo, aunque poner sus nombres en el texto generaría un dilema para Diánoia al forzarla a violar reglas del anonimato en pro de honrar normas de agradecimiento expreso. Mi compensación personal por el "sacrificio" de que sus nombres no figuren expresamente es agradecerles enfáticamente. En segundo lugar, quiero mencionar a algunos de los filósofos que, de manera informal o en discusiones formales en el Instituto, me han enriquecido a mí y a este texto en particular con sus agudos comentarios. A riesgo de olvidar algunos nombres, por lo que me apresuro a ofrecer disculpas, quiero agradecer a Mark Platts, quien durante una inolvidable comida me sugirió incisivas ideas sobre la idea de "residuo moral". A Larry Laudan por nuestras múltiples charlas, algunas de varias horas de duración. A Ricardo Maliandi por nuestras interminables discusiones personales y por correo electrónico. También a Federico Marulanda, Anthony Booth, Xavier de Donato, William Grundy, Emiliano Boccardi (mis colegas de estancia y estimados amigos); a Amalia Amaya, Juan Antonio Cruz Parcero, Pablo Navarro, Gustavo Ortiz Millán, Carlos Pereda (que replicara mi trabajo durante una sesión del Instituto), Faviola Rivera, Nora Rabotnikof, Pablo Muchnick, Miguel Ángel Fernández, Roberto Parra, Adalberto de Hoyos, René González de la Vega, Ignacio Vilaró, Matías Gariazzo, Javier Salcedo, Andrea Lozano, Jorge Ladrón de Guevara y Jorge Cerdio. A mis estudiantes del curso de posgrado "Dilemas morales y derecho", que dicté en el Instituto para los seminarios de Ética del posgrado de la Facultad de Filosofía de la UNAM. Y, por último, a Carla Bagnoli, por nuestros últimos intercambios informales y por haberme abierto a sus siempre estimulantes trabajos sobre dilemas y filosofía moral. 
Ausín, T., 2005, Entre la lógica y el derecho. Paradojas y conflictos normativos, pról. Concha Roldán, Plaza y Valdés, México.

Bagnoli, C., 2006a, Dilemmi Morali, De Ferrari, Italia.

_ $2006 \mathrm{~b}$, "Breaking Ties: The Significance of Choice in Symmetrical Moral Dilemmas", Dialectica, vol. 60, no. 2, pp. 1-14.

_ 2000 , "Value in the Guise of Regret", Philosophical Explorations, vol. 3, no. 2, pp. 165-187.

Balkin, J., 1998, "The Meaning of Constitutional Tragedy", en Eskridge y Levinson 1998, pp. 121-128.

Barberis, M., 2008, Ética para juristas, trad. Álvaro Núñez Vaquero, Trotta, Madrid.

Barcan, M.R., 1987, "Moral Dilemmas and Consistency", en Gowans 1987, pp. 188-204.

Barry, B., 1984, "Tragic Choices", Ethics, vol. 94, no. 2, pp. 303-318.

Baumann, P. y M. Betzler (comps.), 2004, "Introduction", Practical Conflicts. New Philosophical Essays, Cambridge University Press, Cambridge, pp. 126.

Beistegui, Miguel de, y Simon Sparks (comps.), 2000, Philosophy and Tragedy. Warwick Studies in European Philosophy, Routledge, Londres.

Blackburn, S., 1996, "Dilemmas: Dithering, Plumping, and Grief", en Mason 1996, pp. 127-139.

Booth, A., inédito, "Doxastic Regret", manuscrito inédito consultado por gentileza del autor.

Chang, R., 2004, "All Things Considered", Philosophical Perspectives, vol. 18, no. 1 , pp. 1-22.

(comp.), 1997, Incommensurability, Incomparability and Practical Reason, Harvard University Press, Cambridge.

Conee, E., 1987, "Against Moral Dilemmas", en Gowans 1987, pp. 239-249.

Copp, D., 2001, Morality, Normativity, and Society, Oxford University Press, Oxford.

Cruz Parcero, J.A., 2007, El lenguaje de los derechos. Ensayo para una teoría estructural de los derechos, Trotta, Madrid.

De Haan, J., 2001, "The Definition of Moral Dilemmas: A Logical Problem", Ethical Theory and Moral Practice, vol. 4, no. 3, pp. 267-284.

Eskridge, W. y S. Levinson (comps.), 1998, Constitutional Stupidities, Constitutional Tragedies, New York University Press, Nueva York/Londres.

Fuller, L., 1989, El caso de los exploradores de cavernas, trad. Genaro Carrió, Abeledo Perrot, Buenos Aires.

Foot, Ph., 2002, Moral Dilemmas and Other Topics in Moral Philosophy, Oxford University Press, Oxford.

Gowans, C. (comp.), 1987, Moral Dilemmas, Oxford University Press, Oxford. Greenspan, P.S., 1995, Practical Guilt. Moral Dilemmas, Emotions and Social Norms, Oxford University Press, Oxford. 
Günther, K., 1995, "Un concepto normativo de coherencia para una teoría de la argumentación jurídica", Doxa. Cuadernos de Filosofía del Derecho, nos. 1718, pp. 271-302.

Habermas, J., 2006, "La religión en la esfera pública. Los presupuestos cognitivos para el uso público de la razón de los ciudadanos religiosos y seculares", en Entre naturalismo y religión, trad. P. Fabra, D. Gamper, F.J. Gil, J.L. López de Lizaga, P. Madrigal y J.C. Velasco, Paidós, Barcelona, pp. 121-158.

Hill Jr., Th., 1996, "Moral Dilemmas, Gaps, and Residues: A Kantian Perspective", en Mason 1996, pp. 167-198.

Holbo, J., 2002, "Moral Dilemmas and the Logic of Obligation", American Philosophical Quaterly, vol. 39, no. 3, pp. 259-274.

Hooker, B. y M. Little (comps.), 2000, Moral Particularism, Clarendon, Oxford. Hurst, J., 2002, La historia de las ideas sobre el aborto en la Iglesia católica. Lo que no fue contado, Católicas por el Derecho a Decidir, México.

Hursthouse, R., 2001, On Virtue Ethics, Oxford University Press, Oxford.

Kooi, B. y A. Tamminga, 2008, "Moral Conflicts between Groups of Agents", Journal of Philosophical Logic, vol. 37, no. 1, pp. 1-21.

Larmore, Ch., 2001, Patterns of Moral Complexity, Cambridge University Press, Cambridge.

Lemmon, E.J., 1987, "Moral Dilemmas", en Gowans 1987, pp. 101-114.

Levi, I., 1997, "Conflict and Inquiry", en I. Levi, The Covenant of Reason. Rationality and the Commitments of Thought, Cambridge University Press, Cambridge, pp. 217-238.

Maliandi, R., 2006, Ética: dilemas y convergencias. Cuestiones éticas de la identidad, la globalización y la tecnología, Biblos, Buenos Aires.

Maniaci, G., 2004, "Algunas notas sobre coherencia y balance en la teoría de Robert Alexy", Isonomía. Revista de Teoría y Filosofía del Derecho, no. 20, pp. 137-177.

Martínez Zorrilla, D., 2007, Conflictos constitucionales, ponderación e indeterminación normativa, Marcial Pons, Madrid.

Mason, H.E. (comp.), 1996, Moral Dilemmas and Moral Theory, Oxford University Press, Oxford.

McConnell, T., 2002, "Moral Dilemmas" [en línea], Stanford Encyclopedia of Philosophy, modificado el 16 de mayo de 2006, disponible en <http://plato. stanford.edu/entries/moraldilemmas $>$.

_ 1978, "Moral Dilemmas and Consistency in Ethics", Canadian Journal of Philosophy, vol. 8, no. 2, pp. 269-287; incluido también en Gowans 1987, pp. 154-173.

McDowell, J., 1998, "Virtue and Reason", en Mind, Value, and Reality, Harvard University Press, Cambridge, Mass., pp. 50-73.

Moreso, J.J., 2002, "Guastini sobre la ponderación", Isonomía. Revista de Teoría y Filosofía del Derecho, no. 17, pp. 227-249.

Mothersill, M., 1996, “The Moral Dilemmas Debate", en Mason 1996, pp. 6685. 
Nagel, Th., 1987, "The Fragmentation of Value", en Gowans 1987, pp. 174187; también incluido en Mortal Questions, Cambridge University Press, Cambridge, 1987, pp. 128-141.

Nussbaum, M., 2009, La terapia del deseo. Teoría y práctica en la ética helenísti$c a$, trad. Miguel Candel, Paidós, Barcelona.

Nussbaum, M., 2005, El conocimiento del amor. Ensayos sobre filosofía y literatu$r a$, trad. Rocío Orsi Portalo y Juana María Inarejos Ortiz, Antonio Machado Libros, Madrid.

— 1986, The Fragility of Goodness. Luck and Ethics in Greek Tragedy and Philosophy, Cambridge University Press, Cambridge.

Ortiz Millán, G., 2008, "Argumentos sobre el aborto", manuscrito inédito consultado por gentileza del autor. De próxima aparición en Siglo XXI Editores.

— Revista Internacional de Filosofía, vol. 29, no. 1, pp. 9-36.

Peña, L., 1991, "Los dilemas morales en la filosofía analítica", Isegoría, no. 3, pp. 43-79.

Platón, 1993, La República, trad. José Manuel Pabón y Manuel Fernández Galiano, Atalaya, Madrid.

Platts, M., 2006, "Escepticismo filosófico y obligación moral", en M. Platts (comp.), Conceptos éticos fundamentales, Instituto de Investigaciones Filosóficas-UnAM, México, pp. 55-80.

—_, 2000, Dilemas éticos, Fondo de Cultura Económica/Instituto de Investigaciones Filosóficas-UnAM, México.

—_, 1999, "Apéndice: ética y práctica", en M. Platts, Sobre usos y abusos de la moral. Ética, sida y sociedad, Paidós/Instituto de Investigaciones FilosóficasUNAM, México.

Pollock, J., 2004, Ethics in Crime and Justice, Thomson Wadsworth, Belmont.

Post, R., 1998, "Tragedy and Constitutional Interpretation", en Eskridge y Levinson 1998, pp. 217-225.

Quinn, W., 1984, "Abortion: Identity and Loss", Philosophy and Public Affairs, vol. 13, no. 1, pp. 24-54.

Rachels, J., 2007, Introducción a la filosofía moral, trad. Gustavo Ortiz Millán, Fondo de Cultura Económica, México.

Railton, P., 1996, "The Diversity of Moral Dilemma”, en Mason 1996, pp. 140166.

Rawls, J., 1971, A Theory of Justice, Harvard University Press, Cambridge, Mass. [Versión en castellano: Teoría de la justicia, trad. María Dolores González, Fondo de Cultura Económica, México, 1979.]

Richardson, H., 1997, Practical Reasoning about Final Ends, Cambridge University Press, Cambridge.

Rinesi, E., 2003, Política y tragedia. Entre Hamlet y Maquiavelo, Colihue, Buenos Aires.

Rocco, Ch., 2000, Tragedia e Ilustración. El pensamiento politico ateniense y los dilemas de la modernidad, trad. C. Gardini, Andrés Bello Editor, Barcelona. 
Rowan, J., 1999, Conflicts of Rights. Moral Theory and Social Policy Implications, Westview, Boulder.

Ryle, G., 1962, Dilemmas, Cambridge University Press, Cambridge (The Tanner Lectures, 1953).

Salles, R., 2006, Los estoicos y el problema de la libertad, Instituto de Investigaciones Filosóficas-UnAM, México.

Santiago, T. y C. Trueba Atienza (comps.), 2006, De acciones, deseos y razón práctica, Universidad Autónoma Metropolitana-Iztapalapa/Casa Juan Pablos, México.

Sartre, J.-P., 2003, El existencialismo es un humanismo, trad. Manuel Lamana, Losada, Buenos Aires.

Sayre-McCord, G., 2009, "A Moral Argument against Moral Dilemmas", manuscrito inédito consultado con permiso del autor, disponible en línea en $<$ http://ethics-etc.com/2009/01/03/sayre-mccord-on-moral-dilemmas/>.

Scheler, M., 1961, "Acerca del fenómeno de lo trágico", en El santo, el genio, el héroe, trad. Elsa Tabernig, Editorial Nova, Buenos Aires, 143-169.

Sewall, R., 1959, The Vision of Tragedy, Yale University Press, New Haven.

Sinnott-Armstrong, W., 1988, Moral Dilemmas, Basil Blackwell, Oxford.

Sollum, L. y C. Farrelly, 2008, Virtue Jurisprudence, Palgrave Macmillan, Nueva York.

Steiner, G., 2001, La muerte de la tragedia, trad. E.L. Revol, Monte Ávila Editores, Venezuela.

Strawson, P.F., 1974, Freedom and Resentment and Other Essays, Methuen, Londres.

Thomson, J.J., 2001, "Una defensa del aborto", trad. Margarita M. Valdés, en Valdés 2001a, pp. 187-207.

Trueba Atienza, C., 2006, "Phrónesis y verdad práctica", en Santiago y Trueba 2006, pp. 69-88.

—_, 2004, Ética y tragedia en Aristóteles, Anthropos/Universidad Autónoma Metropolitana-Iztapalapa, México.

Valdés, M.M., 2004, "El problema del aborto: tres enfoques", en Rodolfo Vázquez (comp.), Bioética y derecho. Fundamentos y problemas actuales, Fondo de Cultura Económica/ITAM, México, pp. 129-150.

- (comp.), 2001a, Controversias sobre el aborto, Fondo de Cultura Económica/Instituto de Investigaciones Filosóficas-UNAM, México.

—_, 2001b, “Introducción”, en Valdés 2001a, pp. 7-21.

Vallentyne, P., 1992, "Moral Dilemmas and Comparative Conceptions of Morality", Southern Journal of Philosophy, vol. 30, no. 1, pp. 117-124.

Waldron, J., 1993, "Rights in Conflict", en J. Waldron, Liberal Rights, Cambridge University Press, Cambridge.

Wenz, P., 2007, Political Philosophies in Moral Conflict, McGraw Hill, Boston.

Williams, B., 2006, "El reconocimiento de la responsabilidad", trad. Laura Manríquez, en Mark Platts (comp.), Conceptos éticos fundamentales, Instituto de Investigaciones Filosóficas-UNAM, México, pp. 167-199. 
__ 1993, "Conflicto de valores", en La fortuna moral, trad. Susana Marín, Instituto de Investigaciones Filosóficas-UNAM, México, pp. 97-110.

— 1987, "Ethical Consistency", en Gowans 1987, pp. 115-137.

Williams, B. y J.J.C. Smart, 1973, Utilitarianism: For and Against, Cambridge University Press, Cambridge.

Winch, P., 1972, "The Universalizability of Moral Judgments", en Ethics and Action, Routledge and Kegan, Londres, pp. 151-170.

Zagzebski, L., 1996, Virtues of the Mind. An Inquiry into the Nature of Virtue and the Ethical Foundations of Knowledge, Cambridge University Press, Cambridge.

Zagal, H., 2006, "Virtud y verdad práctica en la Ética Nicomaquea", en Santiago y Trueba Atienza 2006, pp. 55-68.

Zucca, L., 2009, "The Crisis of the Secular State. A Reply to Professor Sajó", manuscrito inédito consultado por gentileza del autor. [Publicado en International Journal of Constitutional Law, vol. 7, no. 3, 2009, pp. 494-514.]

— 2007, Constitutional Dilemmas. Conflicts of Fundamental Legal Rights in Europe and USA, Oxford University Press, Oxford.

Zucca, L. y S. Cvijic, 2004, "Does European Constitution Need Christian Values?", Oxford Journal of Legal Studies, vol. 24, no. 4, pp. 739-748.

Recibido el 18 de septiembre de 2008; aceptado el 14 de octubre de 2010.

Diánoia, vol. LV, no. 64 (mayo 2010). 